\title{
Ambient seismic noise tomography of Canada and adjacent regions: Part I. Crustal structures
}

\author{
Honn Kao, ${ }^{1,2}$ Yannik Behr, ${ }^{3,4}$ Claire A. Currie, ${ }^{5}$ Roy Hyndman, ${ }^{1,2}$ John Townend, ${ }^{4}$ \\ Fan-Chi Lin, ${ }^{6}$ Michael H. Ritzwoller, ${ }^{7}$ Shao-Ju Shan, ${ }^{1}$ and Jiangheng $\mathrm{He}^{1}$ \\ Received 17 July 2013; revised 25 October 2013; accepted 29 October 2013; published 21 November 2013.
}

[1] This paper presents the first continental-scale study of the crust and upper mantle shear velocity $\left(V_{s}\right)$ structure of Canada and adjacent regions using ambient noise tomography. Continuous waveform data recorded between 2003 and 2009 with 788 broadband seismograph stations in Canada and adjacent regions were used in the analysis. The higher primary frequency band of the ambient noise provides better resolution of crustal structures than previous tomographic models based on earthquake waveforms. Prominent low velocity anomalies are observed at shallow depths $(<20 \mathrm{~km})$ beneath the Gulf of St. Lawrence in east Canada, the sedimentary basins of west Canada, and the Cordillera. In contrast, the Canadian Shield exhibits high crustal velocities. We characterize the crust-mantle transition in terms of not only its depth and velocity but also its sharpness, defined by its thickness and the amount of velocity increase. Considerable variations in the physical properties of the crust-mantle transition are observed across Canada. Positive correlations between the crustal thickness, Moho velocity, and the thickness of the transition are evident throughout most of the craton except near Hudson Bay where the uppermost mantle $V_{s}$ is relatively low. Prominent vertical $V_{s}$ gradients are observed in the midcrust beneath the Cordillera and beneath most of the Canadian Shield. The midcrust velocity contrast beneath the Cordillera may correspond to a detachment zone associated with high temperatures immediately beneath, whereas the large midcrust velocity gradient beneath the Canadian Shield probably represents an ancient rheological boundary between the upper and lower crust.

Citation: Kao, H., Y. Behr, C. A. Currie, R. Hyndman, J. Townend, F.-C. Lin, M. H. Ritzwoller, S.-J. Shan, and J. He (2013), Ambient seismic noise tomography of Canada and adjacent regions: Part I. Crustal structures, J. Geophys. Res. Solid Earth, 118, 5865-5887, doi:10.1002/2013JB010535.

\section{Introduction}

[2] The continental lithosphere of Canada contains a record of tectonic events that have shaped the region over the last $4 \mathrm{Gyr}$, from the ancient orogens that formed the cratonic core to ongoing deformation of the more juvenile accreted

Additional supporting information may be found in the online version of this article.

${ }^{1}$ Geological Survey of Canada, Pacific Geoscience Centre, Sidney, British Columbia, Canada.

${ }^{2}$ School of Earth and Ocean Sciences, University of Victoria, Victoria, British Columbia, Canada.

${ }^{3}$ Swiss Seismological Service, ETH Zurich, Zurich, Switzerland.

${ }^{4}$ School of Geography, Environment, and Earth Sciences, Victoria University of Wellington, Wellington, New Zealand.

${ }^{5}$ Department of Physics, University of Alberta, Edmonton, Alberta, Canada.

${ }^{6}$ Division of Geological and Planetary Sciences, California Institute of Technology, Pasadena, California, USA.

${ }^{7}$ Department of Physics, University of Colorado Boulder, Boulder, Colorado, USA.

Corresponding author: H. Kao, Geological Survey of Canada, Pacific Geoscience Centre, 9860 W. Saanich Rd., Sidney, B.C. V8L 4B2, Canada. (hkao@nrcan.gc.ca)

(C2013. American Geophysical Union. All Rights Reserved. 2169-9313/13/10.1002/2013JB010535 terranes of the Canadian Cordillera. This area, which extends for $>3000 \mathrm{~km}$ between the Atlantic and Pacific Oceans and a similar distance north-south (Figure 1), can be divided into three major geological domains: orogenic belts (the tectonically active Cordillera in the west and the inactive Appalachian and Innuitian in the east and north, respectively), the central Archean shield, and the surrounding younger platforms (including sedimentary basins underlain by Archean rocks) [e.g., Fulton, 1989; Vincent, 1989; Wheeler et al., 1997]. Present-day tectonic activity occurs mainly in the west in the Cordillera, where subduction of the Juan de Fuca and Explorer plates beneath the North America plate takes places in the south and mainly strike-slip motion between North America and the Pacific plate takes place further north (Figure 1). The last tectonic events in the east Appalachian and Arctic Innuitian regions were the Taconic orogeny in the Early Paleozoic and the Eurekan orogeny in the Early Paleocene, respectively [Okulitch and Trettin, 1991; Williams, 1979]. The tectonic history of Canada thus varies dramatically from west to east, and there are associated significant variations in lithospheric structure as explored in this study.

[3] Global and regional tomographic studies using earthquake sources have identified the systematic seismic velocity differences between the continent's cratonic center and the 


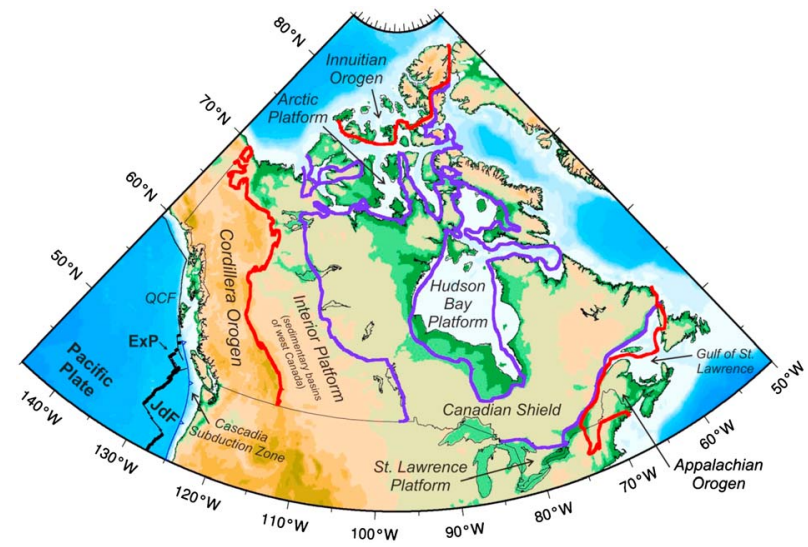

Figure 1. Topography map of Canada showing major geological and tectonic settings. Thick purple lines mark the boundaries between the Canadian Shield, where the Archean craton is exposed, and stable platforms, where sedimentary rocks are underlain by the craton. Thick red lines mark the boundaries between stable platforms and orogenic belts. Jdf: Juan de Fuca plate; ExP: Explorer plate; QCF: Queen Charlotte fault.

Cordillera and Cascadia subduction zone in the west [Dalton et al., 2009; Lebedev and van der Hilst, 2008; Lekic and Romanowicz, 2011; Mercier et al., 2009; Simmons et al., 2010; van der Lee and Frederiksen, 2005, and references therein]. The lateral transition from high upper mantle velocities associated with the cold craton to lower velocities beneath the hot Cordillera is abrupt [e.g., Hyndman and Lewis, 1999], but geographically complex [e.g., Bank et al., 2000; Bensen et al., 2008; Frederiksen et al., 1998; Mercier et al., 2009; van der Lee and Frederiksen, 2005]. Similarly, variations in crustal thickness across the continent have been extensively documented, with average to thick (40-45 km) crust in the craton and other stable areas in the middle of the continent [e.g., Cook et al., 2010; Ma et al., 2012; Mooney et al., 1998; Perry et al., 2002] and thin $(\sim 35 \mathrm{~km})$ crust beneath the Cordillera [Clowes et al., 2005; Mooney et al., 1998; Perry et al., 2002]. Numerous studies have addressed aspects of the seismic and thermal structures of various parts of the Canadian Shield [e.g., Audet and Mareschal, 2004; Cheng et al., 2002; Frederiksen et al., 2007; GuillouFrottier et al., 1996; Mareschal et al., 2005; Perry et al., 2006; Shapiro et al., 2004b, and references therein] and the Cordillera [e.g., Cassidy, 1995; Frederiksen et al., 1998; Hyndman et al., 2005; Mercier et al., 2009]. However, a detailed understanding of exactly how the transitions in seismic velocity and crustal thickness from craton to Cordillera are accommodated requires a consistent and systematic approach spanning the entire region.

[4] Ambient seismic noise tomography has recently become a well-established velocity mapping technique [e.g., Behr et al., 2011; Bensen et al., 2009; Fulton, 1989; Ritzwoller et al., 2011; Sabra et al., 2005; Shapiro et al., 2005; Tibuleac et al., 2011; Wapenaar et al., 2008]. One of its advantages over traditional earthquake-based tomographic methods is that it does not rely on heterogeneously distributed earthquake sources. Moreover, due to the high-frequency spectral content of the ambient noise used, this technique is particularly well suited to high-resolution imaging of velocity structures at crustal and uppermost mantle depths [Behr et al., 2011; Lin et al., 2007, 2008]. Its recent widespread adoption has been promoted by the rapid expansion of global, regional, and local broadband seismograph networks. Efficient seismic data management and distribution, as well as increasing computational capacity, have also only recently made possible the processing of the large volumes of ambient seismic noise data involved.

[5] Using ambient noise records from Canada and adjacent parts of the United States and Greenland (Figure 2), the goal of this study is to establish the crust and upper mantle velocity structure at a resolution as high as the local and regional data permit and to investigate all the geological provinces with the same methodology and processing procedures. Based on the surface wave tomographic results obtained, we then estimate the 3 -D shear velocity $\left(V_{s}\right)$ distributions to uppermost mantle depths. We focus mainly on crustal and uppermost mantle structures with special emphasis on the topography and character of the Moho discontinuity. Finally, we address how abruptly crustal velocity and thickness vary among the geological provinces and discuss the tectonic implications of these variations.

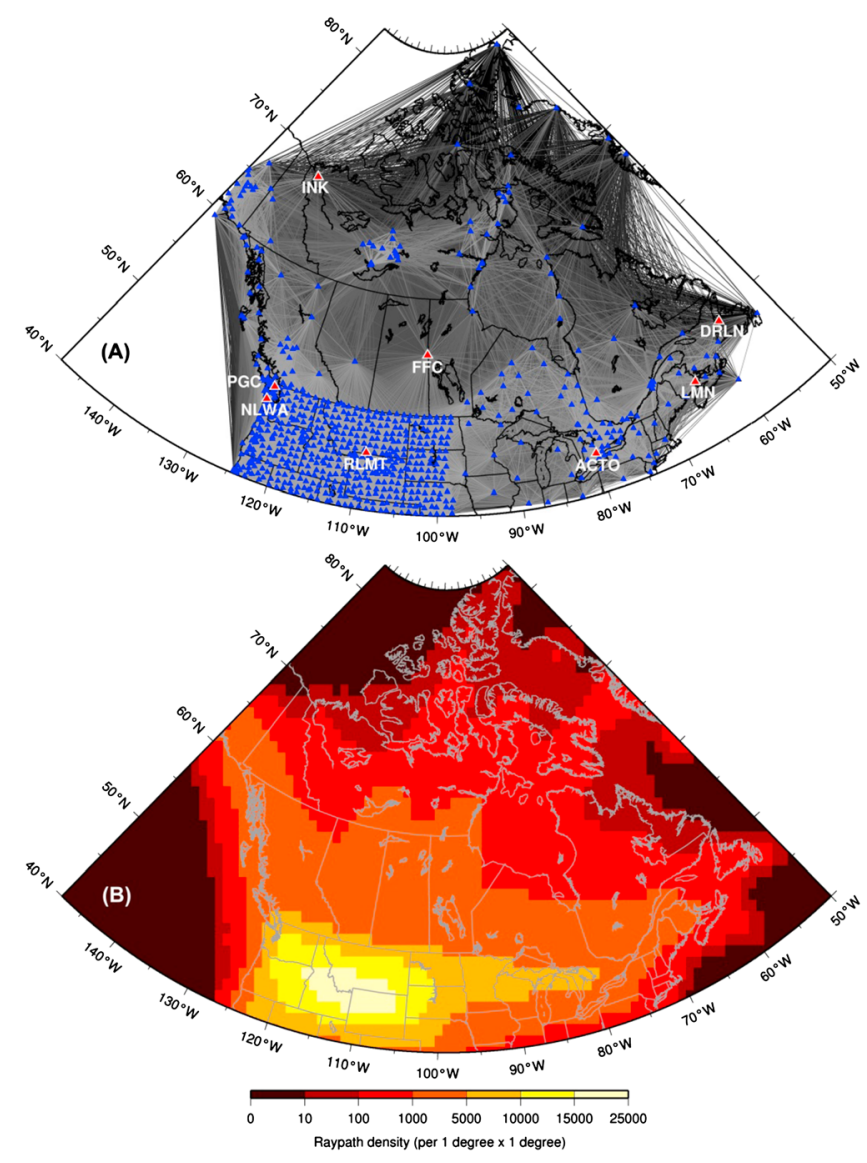

Figure 2. (a) Station distribution and raypath coverage and (b) density of our data set. The color of the raypath varies with the interstation distance (black indicates the longest paths, white indicates the shortest) to better depict the path coverage of different regions. Each blue triangle corresponds to one seismograph station. Red triangles mark the location of stations discussed in the text and subsequent figures. 

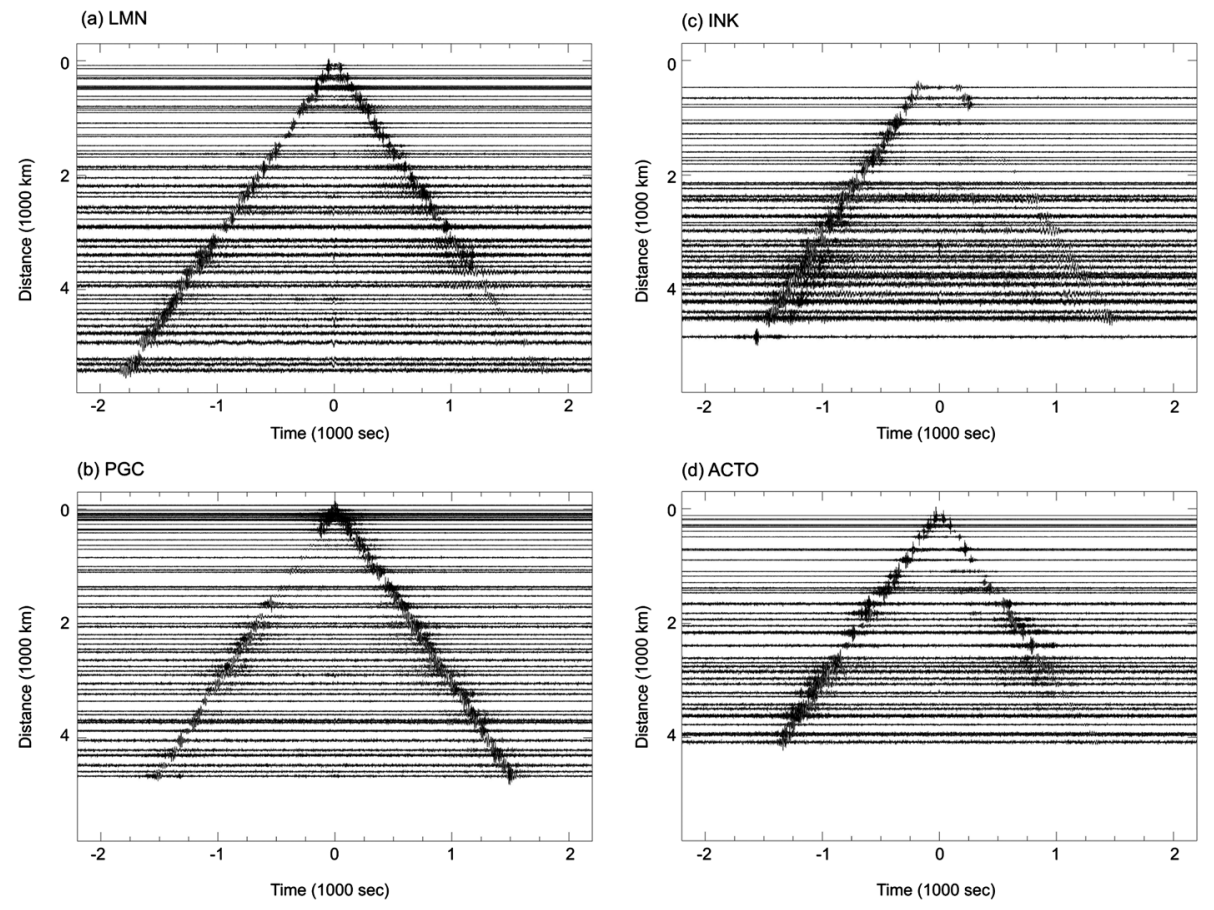

Figure 3. Representative examples of stacked cross-correlation functions from continuous ambient seismic noise data. For each $100 \mathrm{~km}$ distance interval, only the trace with the highest signal-to-noise (SNR) ratio, defined as the ratio between the largest absolute amplitude and the mean absolute amplitude, is plotted. No filter is applied to waveforms. High-pass filtered (corner frequency at $0.1 \mathrm{~Hz}$ ) and low-pass filtered (corner frequency at $0.02 \mathrm{~Hz}$ ) plots are provided in the supporting information (Figures S1 and S2, respectively) for readers who are interested in assessing the data quality at different frequency ranges. Locations of stations are shown in Figure 2.

\section{Data and Analysis}

[6] In this section, we first describe the ambient noise data used in our analysis, followed by an introduction to the data processing procedures, tomographic inversion, and the conversion of surface wave results obtained at different periods to $3-\mathrm{D}$ shear wave velocities.

\subsection{Ambient Seismic Noise Data}

[7] Continuous digital broadband seismic waveforms recorded by the Canadian National Seismograph Network (CNSN) and the Portable Observatories for Lithospheric Analysis and Research Investigating Seismicity (POLARIS) between 2003 and 2009 constitute the core component of our data set. To improve velocity resolution near the boundaries of the main study area, we also used broadband waveforms from stations north of $40^{\circ} \mathrm{N}$ within the United States, mainly from the United States Advanced National Seismic System and the dense temporary United States Transportable Array (USArray). We also used stations east of $150^{\circ} \mathrm{W}$ in Alaska (mainly the Alaska Regional Seismic Network) and along the western coastline of Greenland (included as part of the Global Seismic Network). We further included stations of the Canadian High Arctic Seismic Monitoring Experiment (CHASME) to provide critical data coverage for the Arctic north. Figure 2 shows the station distribution of our data set, the corresponding raypath coverage, and the distribution of raypath density for each $1^{\circ} \times 1^{\circ}$ area.
[8] CNSN, POLARIS, and CHASME waveform archives were obtained from the CNSN Data Center, whereas the other data were obtained from the Data Management Center of the Incorporated Research Institutions for Seismology (IRIS). The combined data set include records from 843 stations covering a time window of 2557 days. Because not all stations operated at the same time, especially those of the USArray, it is not possible to have a complete combination of all station pairs for any given day. On average, our data set has half to two thirds of the stations represented on any 1 day.

\subsection{Seismic Waveform Processing}

[9] We follow the procedures outlined by Bensen et al. [2007] to process the waveform data. For each station, the vertical component waveforms are first split into 1 day segments, followed by the subtraction of the mean and trend, removal of the instrument response, time-domain normalization using the running-absolute-mean method, and spectral whitening. Cross-correlation functions (CCFs) were calculated for the daily waveforms for each station pair. We employ a two-stage stacking scheme, first monthly then total, to accommodate the large volume of data. On average, each station yields more than 12,000 monthly CCFs. For some long-running stations, the number of CCFs exceeds 25,000.

[10] Figure 3 shows four representative examples from CNSN stations of final stacked CCF. Because of the large 
(a) Cross-Correlation Function
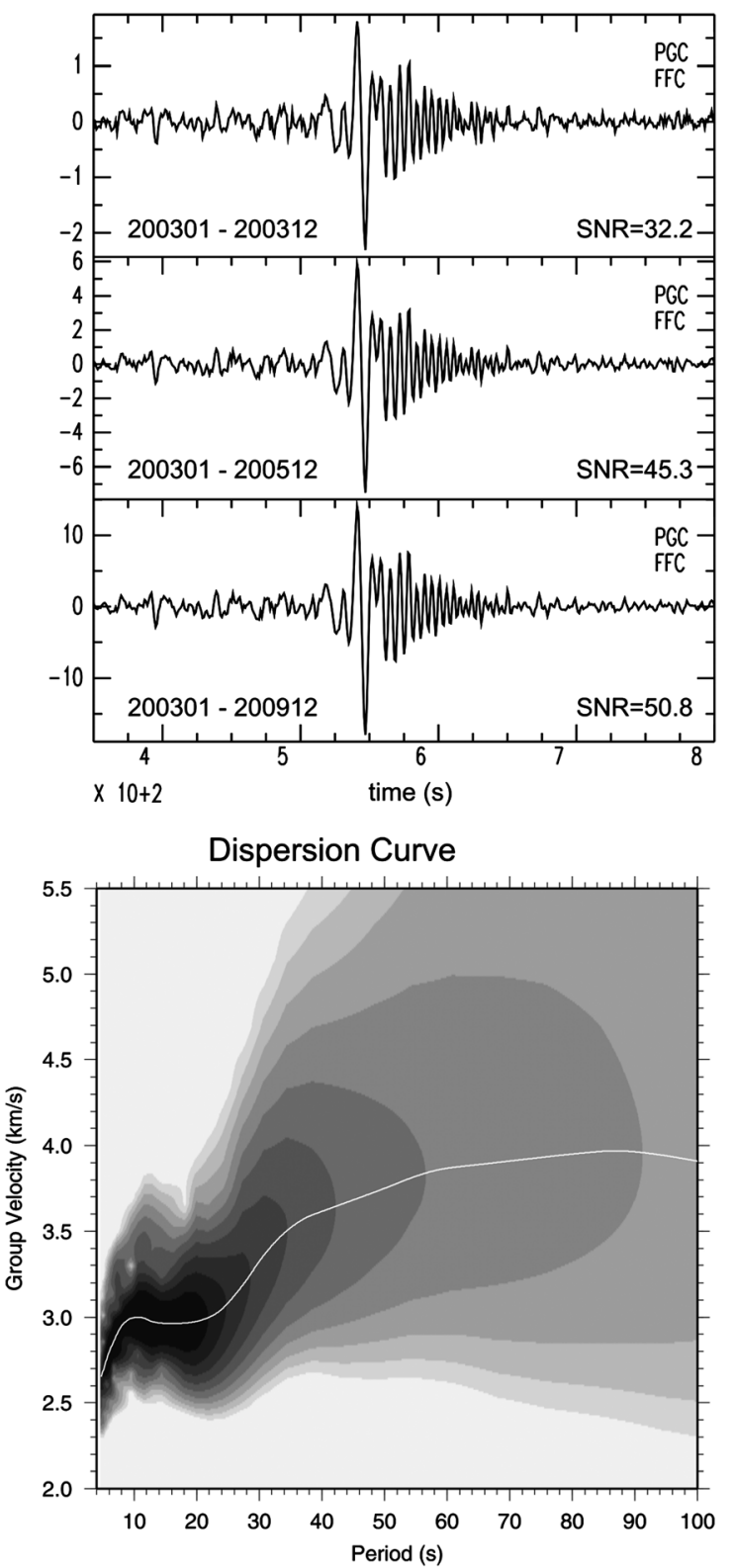

(b) Cross-Correlation Function
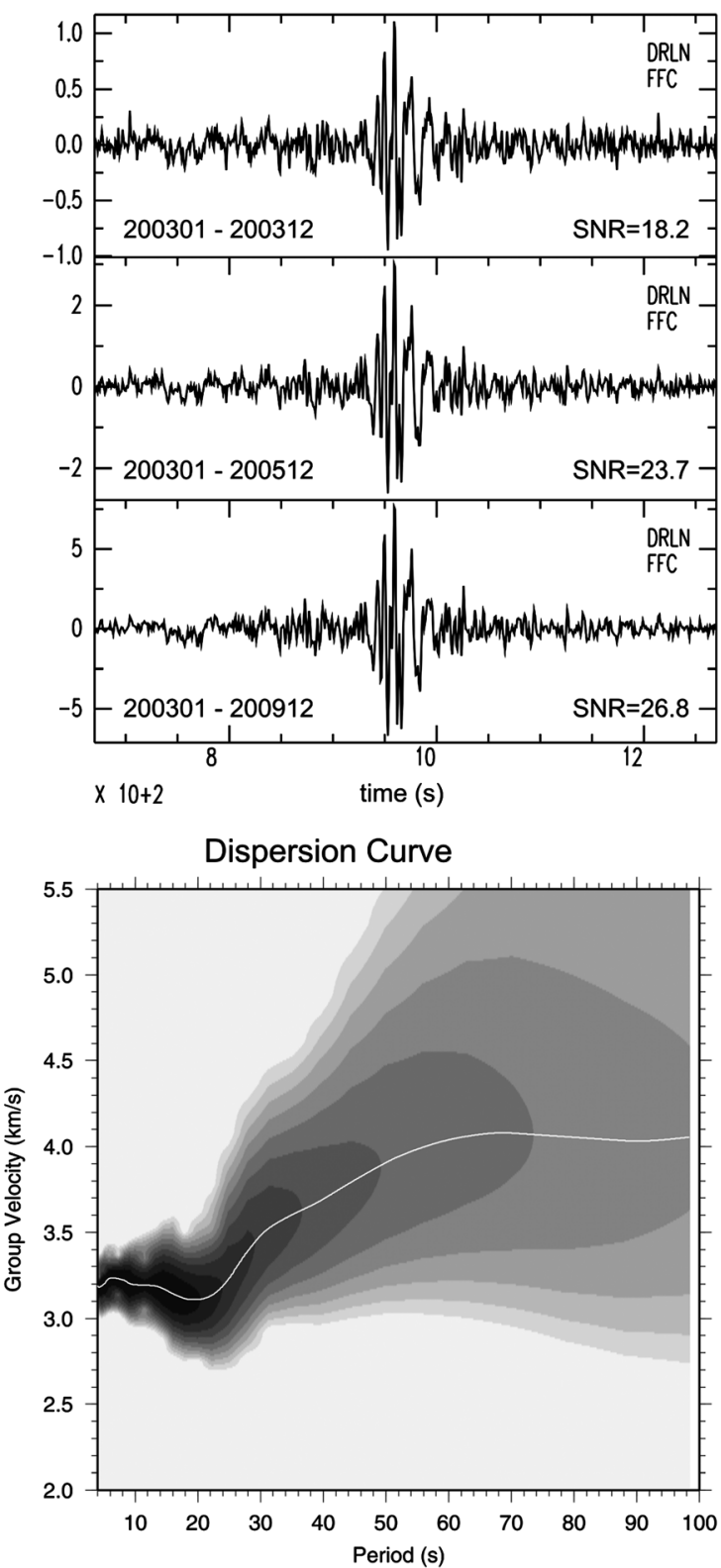

Figure 4. Representative examples of stacked cross-correlation functions using various amount of ambient seismic noise (1 year: top trace; 3 years: middle trace; and 7 years: bottom trace). Notice that the improvement in signal-to-noise ratio (SNR) becomes marginal once the amount of data exceeds 3 years. The result of frequency-time analysis (FTAN) is shown at the lower panel with the determined dispersion curve shown in white.

number of samples, we plot only the trace with the highest signal-to-noise $(\mathrm{S} / \mathrm{N})$ ratio for each $100 \mathrm{~km}$ distance interval. For the two example stations on the east and west coasts (station codes LMN and PGC, respectively; Figures 3a and $3 \mathrm{~b}$ ), the Rayleigh wave moveout can be clearly observed across the continent to offsets of more than $5000 \mathrm{~km}$. For the example stations located in the northwest (INK) and southeast (ACTO), the moveout spans more than $4000 \mathrm{~km}$ (Figures $3 \mathrm{c}$ and $3 \mathrm{~d}$ ). All four stations show pronounced differences between the causal (positive) and acausal (negative) branches of the CCF, which are most likely due to azimuthally biased noise source distributions [e.g., Stehly et al., 2006].

\subsection{Dispersion Measurement}

[11] The positive and negative branches of the correlation function are averaged to give the symmetric component, which is used to estimate Rayleigh wave dispersion curves [Bensen et al., 2007]. The commonly used frequency-time analysis (FTAN) with phase-matched filtering [Levshin and Ritzwoller, 2001] is applied to track the dispersion ridge from the spectral image and to minimize the effects of spurious 
(a) Cross-Correlation Function

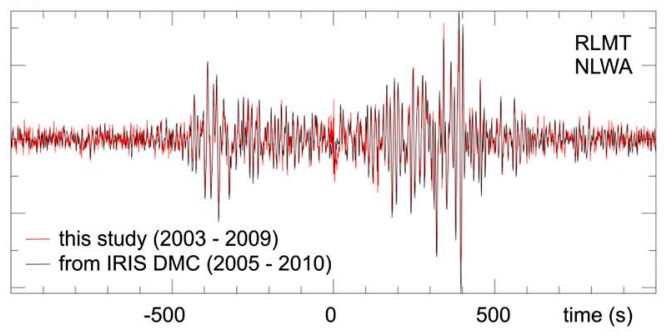

(c) Result of Frequency-Time Analysis (image and red line: this study; white line: IRIS DMC)

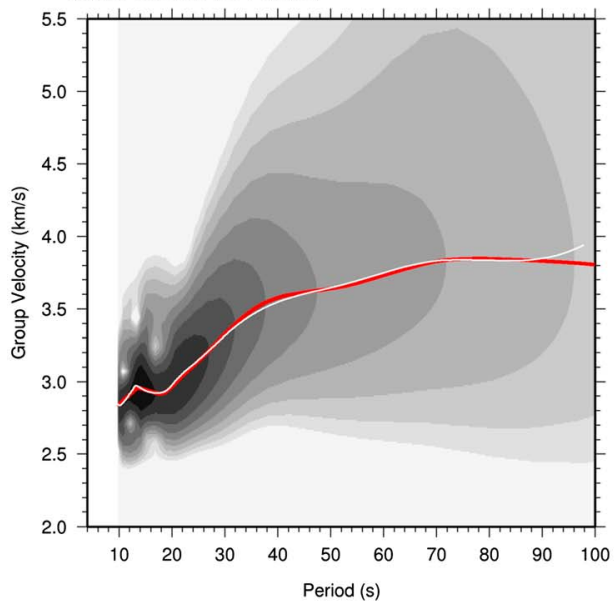

(b) Symmetric Component

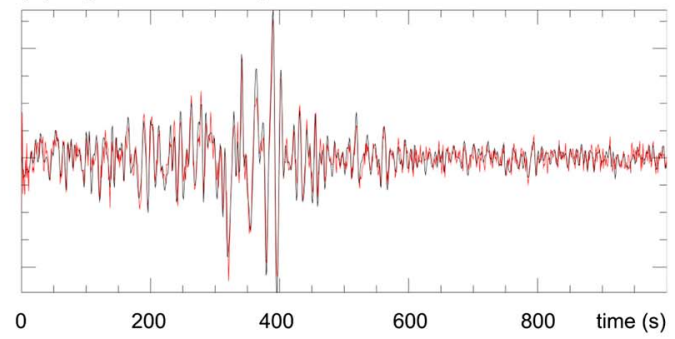

(d) Result of Frequency-Time Analysis (image and white line: IRIS DMC; red line: this study)

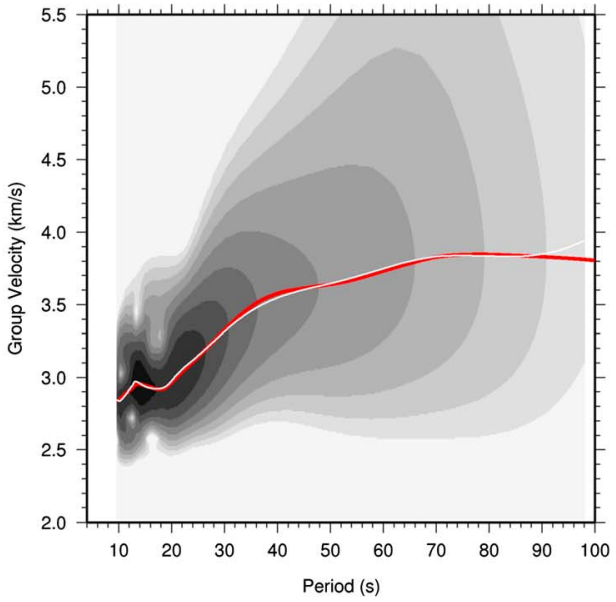

Figure 5. A comparison of (a) the stacked cross-correlation functions, (b) the symmetric component of the cross-correlation function, and (c and d) the dispersion measurements for the station pair RLMT and NLWA. Our results (red traces) and those obtained from the IRIS Data Management Center (black traces) are nearly identical. In the frequency-time analysis, the two patterns are very similar with the dispersion curves (red: this study; white: from IRIS DMC) nearly overlapping up to the period of $91 \mathrm{~s}$.

noise glitches or jumps in group arrival times. The corresponding phase velocities are obtained using the approach described by Lin et al. [2008].

[12] For each station pair, we conduct the phase-matched filtering FTAN for the period range of 5-250 s. If the analysis results in no output, due to an abrupt discontinuity in the dispersion measurements, we incrementally decrease the maximum period (from $250 \mathrm{~s}$ to $200,150,100,75$, or $50 \mathrm{~s}$ ) to maintain both the quantity and quality of our input data.

[13] In Figure 4, we show the stacked symmetric CCFs and the corresponding dispersion curves for two representative station pairs spanning the western (station pair PGCFFC, station distance $1625 \mathrm{~km}$ ) and eastern (station pair DRLN-FFC, station distance $3064 \mathrm{~km}$ ) sides of the Canadian continent, respectively (shown in Figure 2, station locations). The dispersive characteristics of Rayleigh waves can be clearly recognized on traces derived by stacking only 1 year of ambient noise data (Figure 4, top traces). As the duration of the data used in the stacking increases from 1 to 3 years, the $\mathrm{S} / \mathrm{N}$ ratios improve accordingly (Figure 4, middle traces). However, the $\mathrm{S} / \mathrm{N}$ improvement becomes much less significant when we increase the stacking data set from 3 to 7 years (Figure 4, bottom traces), suggesting that the benefit of including data beyond 2009 is probably limited for present purposes.

[14] As our data set covers all the northern states of the U.S. in which ambient noise tomography has been undertaken previously [Bensen et al., 2008, 2009; Shen et al., 2013], it is important to ensure that the stacked CCFs and dispersion measurements derived in this study are consistent with those reported from earlier studies. For this purpose, we compare our results with the stacked CCFs available from the Data Management Center of IRIS [Barmine and Rtizwoller, 2012, IRIS DMS product]. A representative example is shown in Figure 5 (station codes RLMT and NLWA; locations shown in Figure 2). Although the data sets used in the two studies span different years, all the waveform characteristics in the stacked CCF are remarkably similar. The dispersion measurements are essentially identical except at the longest periods (>90 s) where the difference is about $0.2 \mathrm{~km} / \mathrm{s}$ due to the deterioration of data resolution. This provides us with confidence in both the data set and analysis employed in this study.

\subsection{Surface Wave Tomography Inversion}

[15] We use the method of Barmin et al. [2001] to derive tomographic images from Rayleigh wave dispersion data. For each period, the inversion estimates the 2-D distribution of group and phase velocity perturbations across a spherical grid of $1^{\circ}$ spacing in a damped least-squares sense. The damping is controlled by two parameters specifying the weight of smoothing and the width of the smoothing area. We adopt an empirical approach to determine the optimal combination of the two weighting parameters, by systematically examining the mean and standard deviation of the overall misfit function of the inversion. The parameters 
(a) Period $=10 \mathrm{~s}$
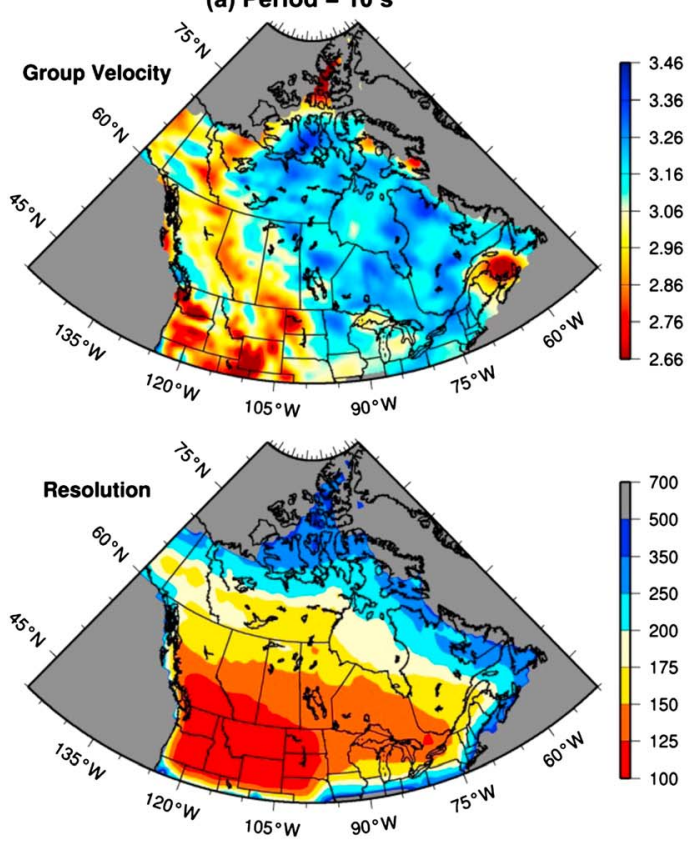

(b) Period $=35 \mathrm{~s}$
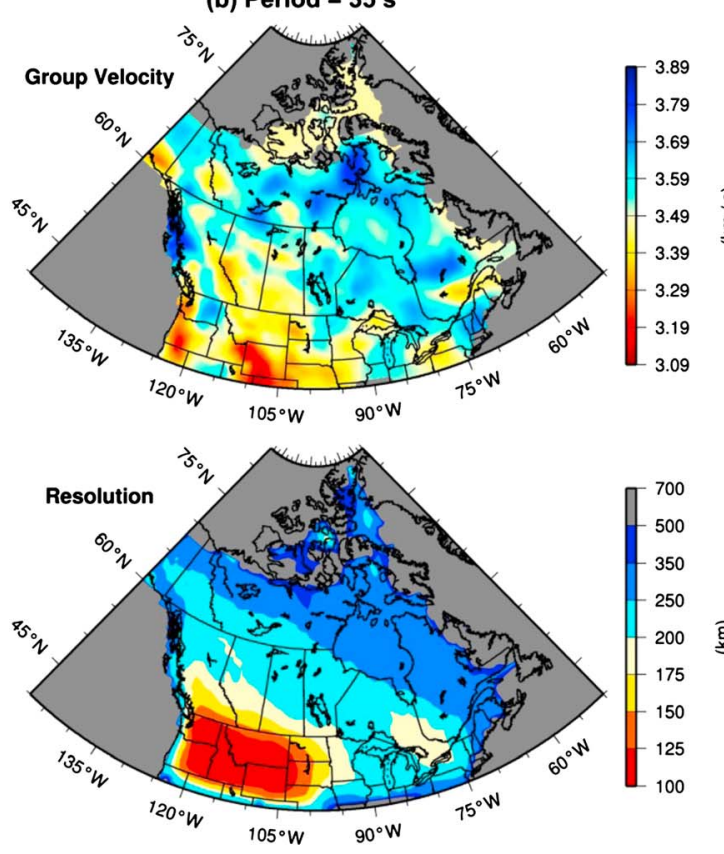
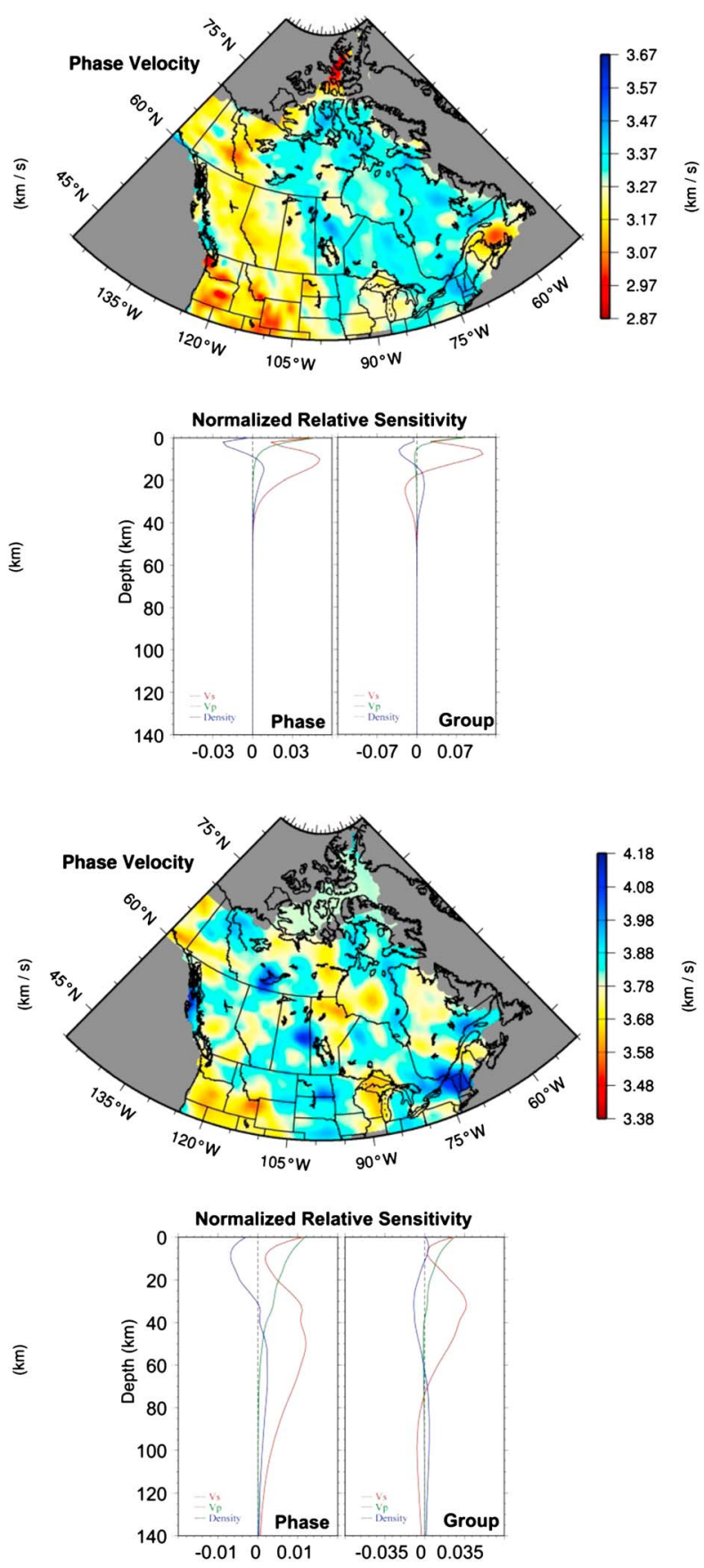

Figure 6. Surface wave tomography inversion results using ambient seismic noise data for the periods of (a) $10 \mathrm{~s}$, (b) $35 \mathrm{~s}$, and (c) $50 \mathrm{~s}$. For each period, the phase and group velocity distributions are shown at the top panels. The bottom panels show the corresponding resolution length as determined from the spike-perturbation test (left) and the depth sensitivity kernel (calculated at the location of $55^{\circ} \mathrm{N}, 110^{\circ} \mathrm{W}$; right).

corresponding to the least damping with a mean misfit close to zero and a small standard deviation are adopted in deriving our final velocity results which are shown in Figure 6. A more detailed discussion of our tomographic inversion results will be given in the next section.

[16] There is no universal consensus in the seismological community on the best resolution assessment for tomography inversion results. Several previous studies have argued that the tomographic resolution inferred from the commonly used checkerboard test may be misleading [e.g., Leveque et al., 1993] or difficult to interpret [e.g., Simons et al., 2002]. In this study, we choose the spike-perturbation test, as outlined by Barmin et al. [2001], to assess the resolution of our results. Specifically, we place a spike-like perturbation at each grid node as the input and obtain the corresponding inversion output. Then, we fit the output with a Gaussian surface and use two standard deviations as the corresponding spatial resolution at that grid node. One advantage of the spike- 

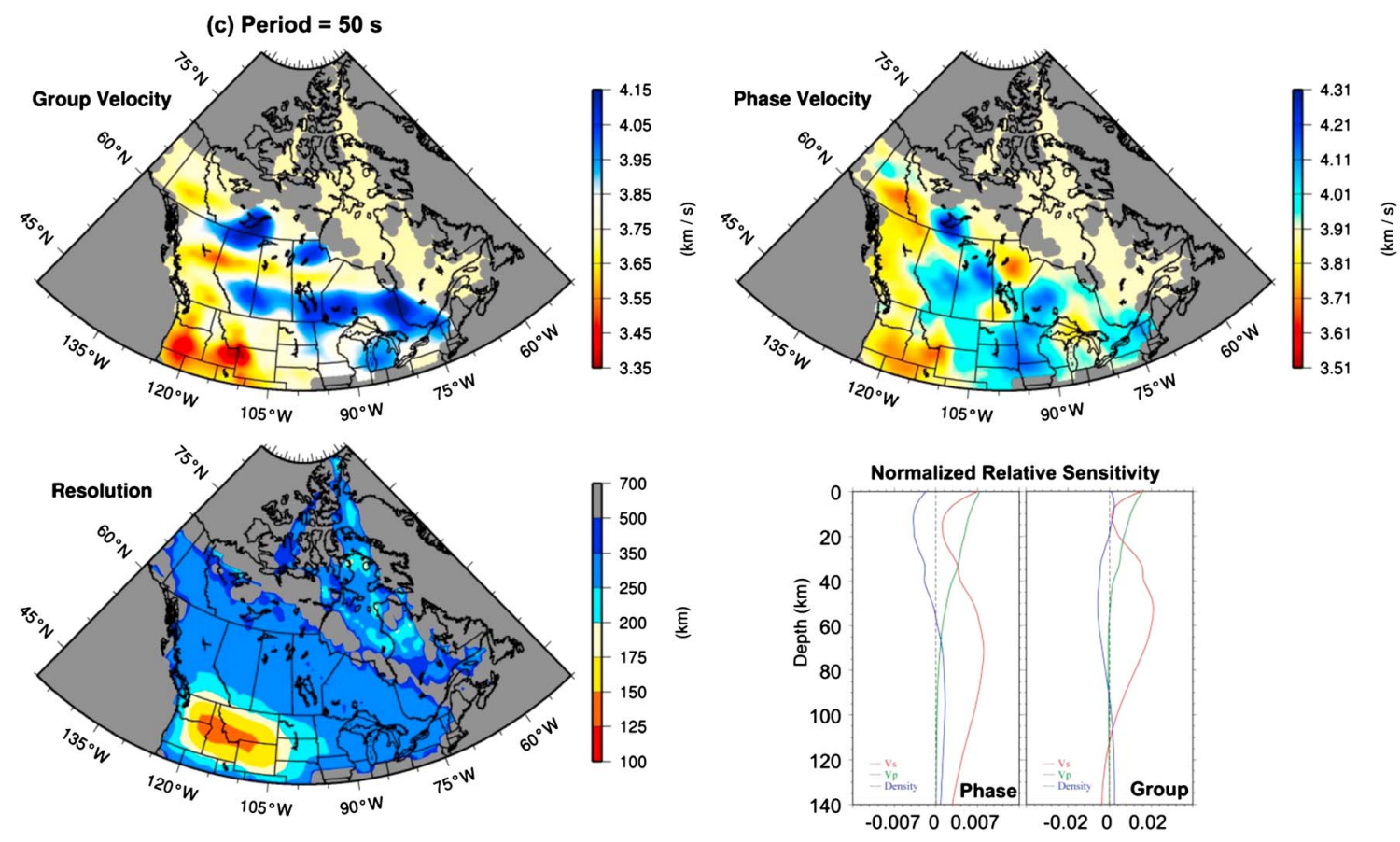

Figure 6. (continued)

perturbation test is that it has a clear physical meaning, i.e., the spatial resolution at that node corresponds to the minimum distance at which a neighboring spike can be unambiguously identified. As expected, we find that the spatial resolution to be closely linked to the density of local stations and the number of raypaths (Figure 2).

\subsection{Conversion From Surface Wave Tomography to 3-D Grid Tomography}

[17] To convert the set of surface wave maps at successive periods into a 3-D shear velocity model, we employ the method of Shapiro et al. [2004a] as implemented by Behr et al. [2010, 2011]. At each $1^{\circ}$ grid point, a new dispersion curve is computed by interpolating between the values at successive periods. Each newly derived dispersion curve is then inverted for a 1-D shear velocity profile using the neighborhood algorithm (NA) [Sambridge, 1999a, 1999b], resulting in 4949 shear velocity-depth profiles. The NA is a direct search method, similar to the Monte Carlo algorithm or simulated annealing, which solves optimization problems by exploring the range of possible solutions in a quasi random manner. It returns best fitting models and an estimate of the distribution of models in the parameter space as a function of their misfit. For each 1-D shear velocity model, the misfit is computed as the least-squares difference between the dispersion curve of the model and the one constructed from the surface wave maps. This approach enables us to evaluate the resolution and the level of ambiguity of each best fitting shear velocity model. We employ the software package Dinver (http://www.geopsy.org) [Wathelet, 2008] which combines the forward modeling algorithm of Dunkin [1965] with an improved version of the original NA. The current version of the Dinver algorithm does not allow for parameterization of a top water layer, and therefore, areas of shallow waters (e.g., lakes or bays) are given a top layer of extremely low shear strength. Inversion results for areas with a thick water column, such as the Pacific and Atlantic Oceans, are disregarded in our analysis.

[18] One hundred new models and their misfits are computed for each of the $300 \mathrm{NA}$ iterations, resulting in 30,000 shear velocity models being evaluated at each grid point. We follow the scheme of CRUST2.0 to parameterize the crustal portion of each model in terms of a stack of five homogeneous, isotropic layers corresponding to sediments, sedimentary basement, upper crust, middle crust, and lower crust. One or two mantle layers are set up to extend the model to upper mantle depths. We assume that the shear modulus is independent of frequency (i.e., shear Q is essentially infinite). This significantly simplifies the forward calculation and can be justified on the ground that our study focus is the crust where $\mathrm{Q}$ tends to be larger than that of the mantle. Also, much of the region of study is stable craton typified by large $\mathrm{Q}$ values. Although a top layer of sediments may have relatively low Q, its effect is generally negligible in our data due to small thickness ( 0 to a few kilometers).

[19] Each layer is characterized by thickness, compressional velocity $\left(V_{p}\right)$, shear velocity $\left(V_{s}\right)$, and density. These parameters systematically vary across Canada depending on the local geological setting at each grid point. The NA varies the thickness, $V_{p}$, and $V_{s}$ but not the density of each layer at each iteration and computes the misfit. Density has been shown to have only minor influence on the resulting dispersion curve [Wathelet, 2005] and has therefore been kept constant at the values of CRUST2.0 in the crust and preliminary reference Earth model (PREM) in the mantle.

[20] To obtain a stable reproducible result, it is necessary to impose some constraints on the parameter space. We achieve this by incorporating a priori knowledge of the shear velocity 

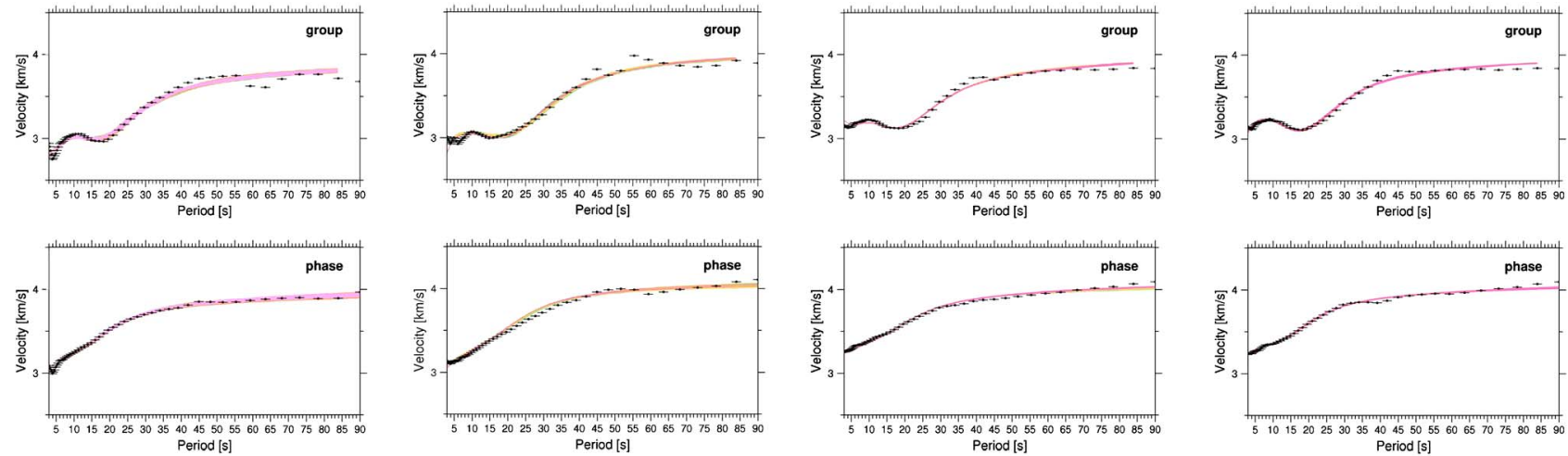

(a) Cordillera

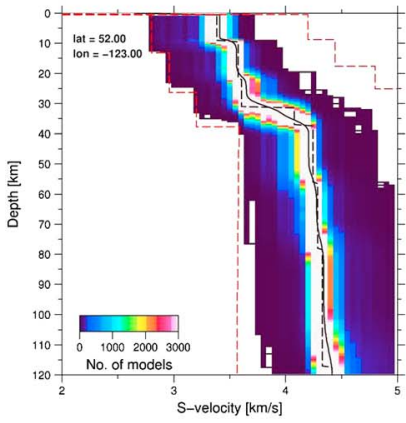

(b) Interior Platform

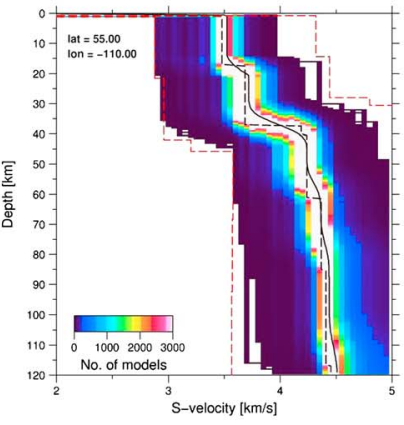

(c) Canadian Shield

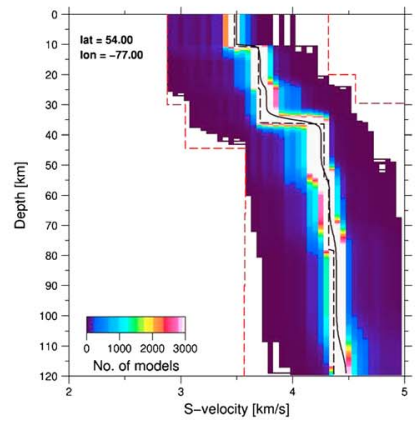

(d) Appalachian

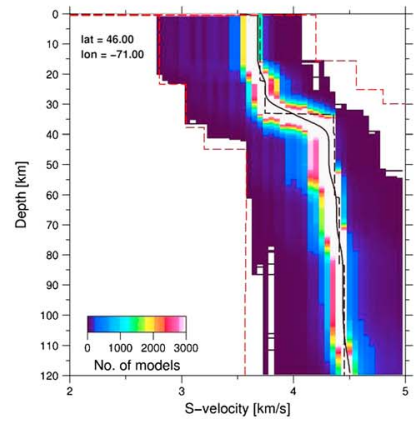

Figure 7. Examples of 1-D shear velocity inversion for four representative grid points. The phase and group velocity dispersion curves are shown at the top and middle panels, respectively. The observed measurements are marked by black plus symbols, whereas the synthetics corresponding to the best fitting model is shown in pink. The Neighborhood algorithm inversion results are shown at the bottom panels. The color of the model space represents the density distribution of samples. The solid and dashed black lines in the middle correspond to the weighted average and the best fitting models, respectively. Dashed red lines mark the sampled model space.

profile at each grid point. For the crust, we allow the NA to vary each inverted parameter by $20 \%$ around the starting model [Bassin et al., 2000]. For the sedimentary layer, upper crust, middle crust, and lower crust, this means that the thickness is allowed to vary in the range of $0-11,4-26,5-24$, and 3-20 km, respectively. The crustal thickness is taken from the LITH5.0 model [Perry et al., 2002], where available, and from CRUST2.0 otherwise. Values for the mantle layers are taken from the PREM model [Dziewonski and Anderson, $1981]$, and we again allow the parameters to vary by $20 \%$.

[21] We take two different approaches to estimate the uncertainty in the inversion results. The first is similar to the statistical method used by Behr et al. [2011]. For each inverted parameter at a given location and depth, we construct a histogram from the top $10 \%$ best fitting models (3000 samples in our case) and then fit the distribution with a Gaussian curve. Two standard deviations are taken as the modeling uncertainty. The second one is a forward modeling approach. For the best fitting model at each grid location, we systematically perturb each inverted parameter and calculate the root-mean-square (RMS) error between the observed and synthetic dispersion curves. Because the overall fit to the phase velocity dispersion curve is $2-3$ times better than the fit to the group velocity [Lin et al., 2008], we adjust the relative weighting between the two by a factor of 2.5 to prevent the uncertainty estimate being dominated by the group velocity misfit. The parameter's range of uncertainty is set at the values corresponding to a 5\% RMS increase.
[22] At each grid point, we calculate the weighted average of the top 5\% best fitting model samples using the inverse of the misfit value as the weighting factor. These weighted best fitting 1-D models are then combined and linearly interpolated between adjacent grid nodes to form the final pseudo 3-D model. The weighted-average approach is a practical

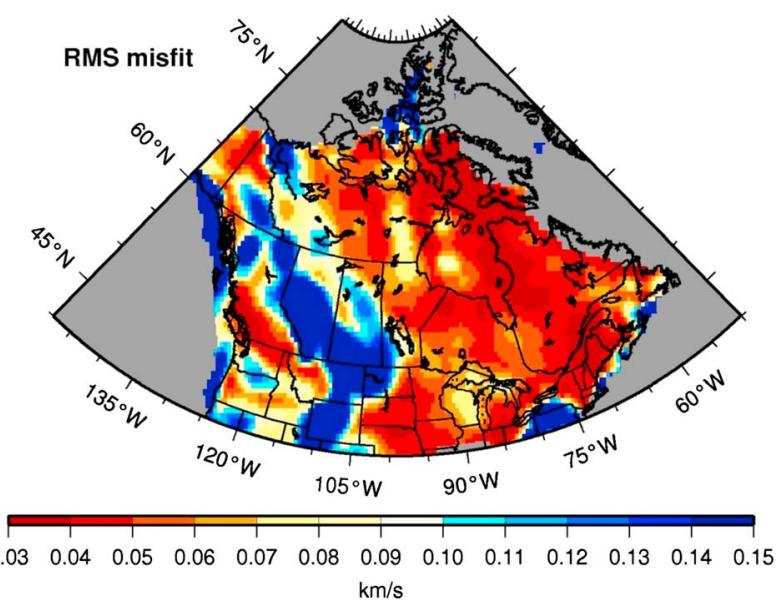

Figure 8. Distribution of the root-mean-square (RMS) misfit of our neighborhood algorithm inversion for the shear velocity structure of Canada and adjacent regions. 

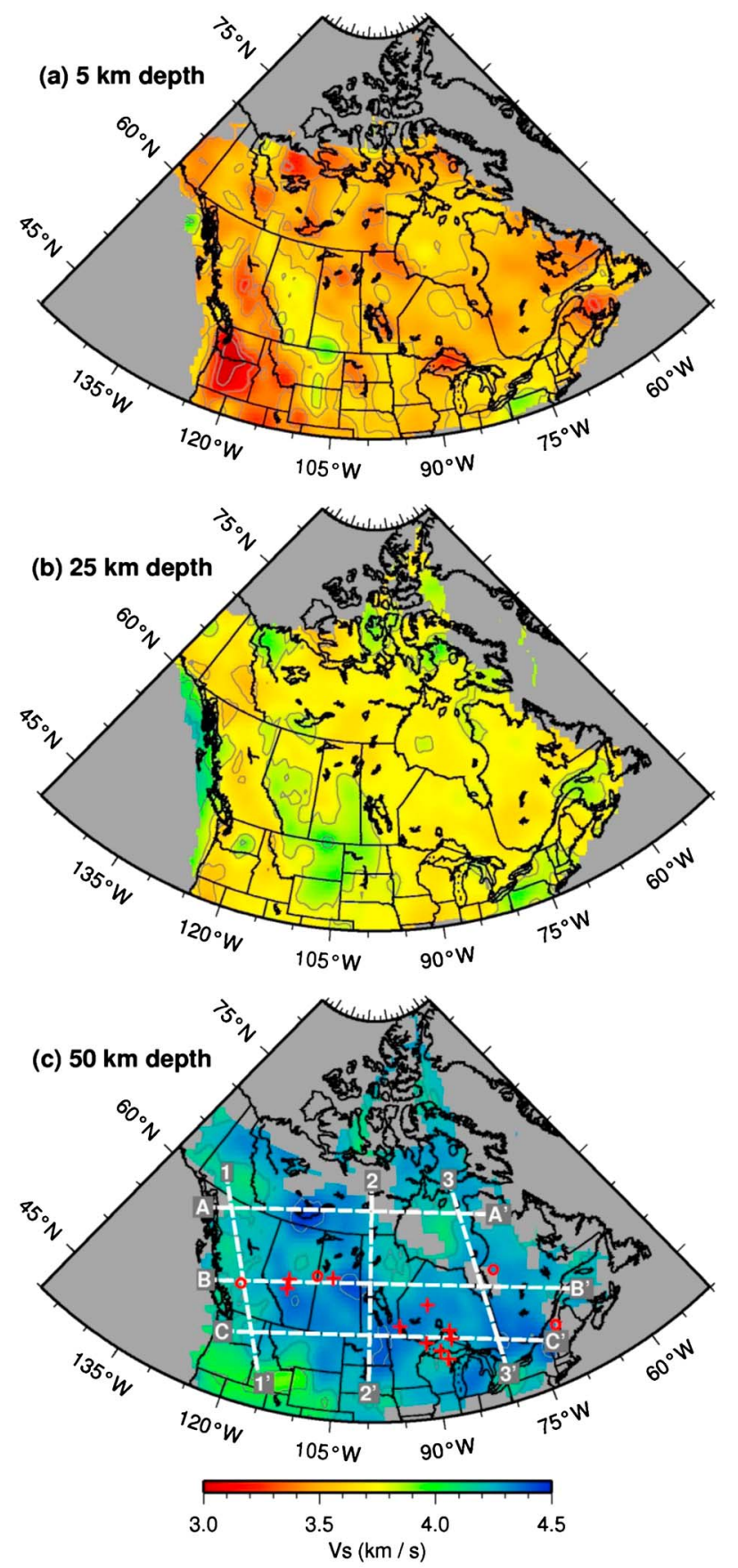

Figure 9. Pseudo 3-D tomography of Canada and its adjacent regions. The distribution of shear velocity at the depths of (a) $5 \mathrm{~km}$, (b) $25 \mathrm{~km}$, and (c) $50 \mathrm{~km}$ is displayed in color with red and blue corresponding to low and high values, respectively. Dashed white lines on the $50 \mathrm{~km}$ image mark the location of cross sections shown in Figure 10, whereas small red circles and crosses correspond to the locations of velocity profiles shown in Figures 7 and 14, respectively.

and perhaps better alternative to choosing the best fitting model, especially when multiple model samples have almost the same misfit.

[23] In Figure 7, we illustrate representative examples of the NA inversion results for points in four different tectonic settings: the Cordillera, the Interior Platform, the Canadian Shield, and the Appalachians (see Figures 1 and 9c for locations). The surface wave dispersion curves are clearly different from one node to another. One important feature in the group velocity dispersion curves is the broad trough in the 15-30 s period range that effectively constrains the depth of the crust-mantle transition [Lebedev et al., 2013]. The trough is the narrowest and shifted toward shorter periods in the Cordillera, where the Moho is generally shallow (Figure 7a). A broader trough is observed within the craton where the crust is thicker (Figures $7 \mathrm{~b}$ and $7 \mathrm{c}$ ). The trough is of intermediate breadth in the Appalachians where the Moho depths are between that of the Cordillera and the craton (Figure 7d).

[24] The robustness of the inversions is well illustrated by the concentration of best fitting models in a relatively narrow portion of the model space (Figure 7). For nearly all the NA inversions that we have performed, the results are robust and can be reproduced with different starting models. Figure 8 shows the distribution of best model misfits. Overall, better results are obtained for the Canadian Shield and the Appalachian regions (misfit $<0.07 \mathrm{~km} / \mathrm{s}$ ) than for the Cordillera and the Interior Platform $(<0.15 \mathrm{~km} / \mathrm{s})$.

\section{Seismic Inversion Results}

[25] In this section, we first present the surface wave tomography results and then the pseudo 3-D shear velocity results computed from ambient seismic noise CCFs. We emphasize the inferred variations in crustal structures, including the depth and velocity characteristics of the Moho. The dominant frequencies of ambient seismic noise are well suited to studying such depths, in contrast to those of most earthquake tomographic studies that focus on lower frequencies and corresponding greater depths.

\subsection{Surface Wave Tomography-General Features}

[26] Since only vertical component waveforms are used in our ambient seismic noise analysis, our surface wave tomography results show the distributions of group and phase velocities of Rayleigh waves. In Figure 6, we show the velocity distributions, horizontal resolution, and depth sensitivities for three periods $(10,35$, and $50 \mathrm{~s})$, which are most sensitive to the depth ranges of 5-15 km, $15-50 \mathrm{~km}$, and $30-80 \mathrm{~km}$, respectively. As described above, the horizontal resolution corresponds to two standard deviations of the best fitting Gaussian surface at each point [Lin et al., 2007], and it appears to correlate closely with the raypath density (Figure S3 in the supporting information).

[27] In general, the group and phase velocity distributions are similar at all periods. At shorter periods (e.g., $10 \mathrm{~s}$, Figure 6a), velocity anomalies are dominated by large-scale sedimentary basins and upper crust structures. Prominent low velocity anomalies are observed for the Gulf of St. Lawrence Basin in the east, the sedimentary basins of west Canada, and in the Cordillera. In contrast, the Canadian Shield generally exhibits high velocities.

[28] The low velocity signature beneath the Gulf of St. Lawrence disappears at periods larger than $35 \mathrm{~s}$. Similarly, the low velocity anomalies associated with the Cordillera are much less visible. Overall, the velocity contrast between high and low anomalies is smaller, and the high velocities 

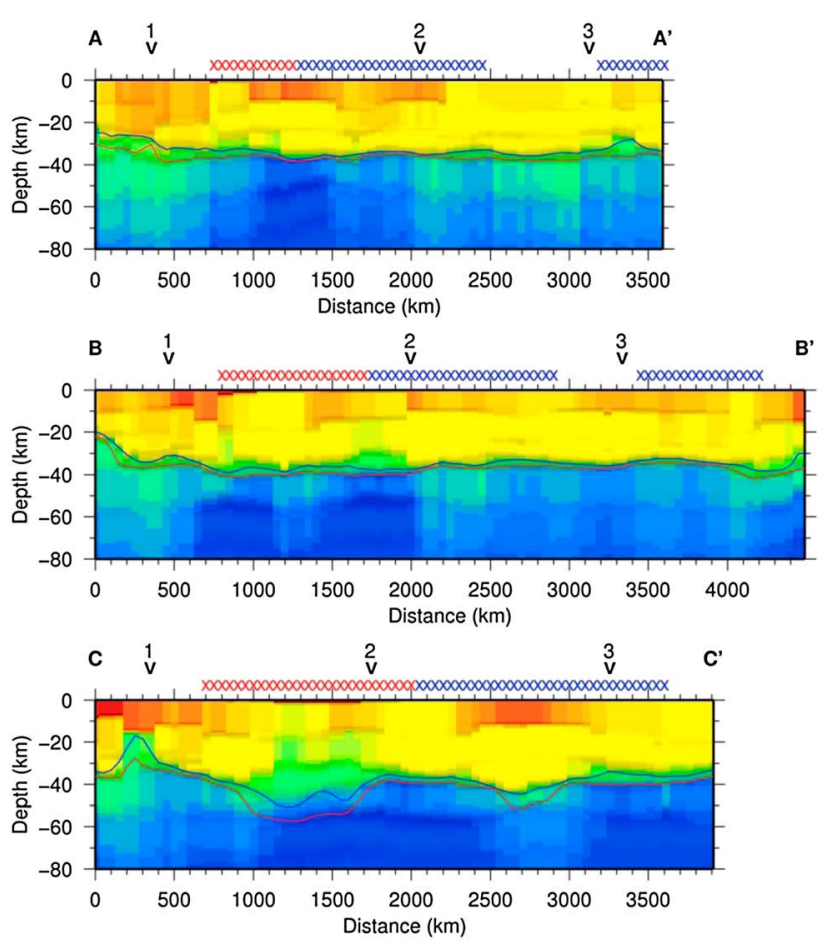
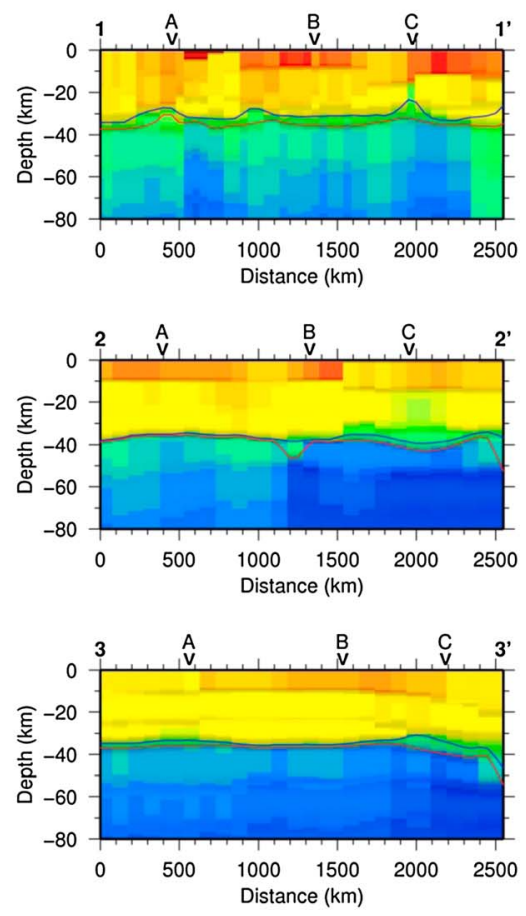

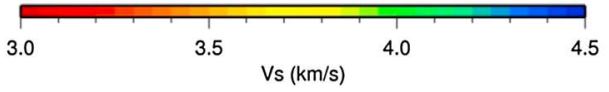

Figure 10. Three east-west (A-A', B-B', and C-C') and three north-south (1-1', 2-2', and 3-3') cross sections showing pseudo 3-D tomography of Canada. Color scale is the same as that in Figure 9. The image is enhanced by shading the illumination in the vertical direction to better display the velocity discontinuities. The black and red lines correspond to the $50 \%$ and $85 \% V_{s}$ increase from crust to upper mantle, respectively, and effectively define the depth range of the crust-mantle transition. Red and blue crosses on the top of Profiles A-A', B-B', and C-C' mark the approximate locations of the Interior Platform and Canadian Shield, respectively. Geographic locations of these cross sections are given in Figure 9c.

associated with the craton extend slightly toward the west under the western Canadian sedimentary basin (i.e., the Interior Platform (Figures 1 and 6b)). Such a westward extension of the high velocity anomaly is even more prominent at longer periods (e.g., 50 s, Figure 6c).

[29] Generally speaking, our data provide reasonable constraints on Rayleigh wave velocities to latitudes of $\sim 70^{\circ} \mathrm{N}$. Further north, the station distribution becomes sparse and the image resolution deteriorates. Taking the $10 \mathrm{~s}$ period as an example, the large volume of data results in a horizontal resolution of $150 \mathrm{~km}$ or less for most grid points south of $55^{\circ} \mathrm{N}$, with the highest resolution found in western U.S. where the station distribution is the densest (Figures 2 and S3). The spatial resolution also deteriorates with increasing period as the total number of useful CCFs decreases from 67,511 at $10 \mathrm{~s}$ to 6,619 at $50 \mathrm{~s}$ (Figure S3). The deterioration becomes progressively worse for the northern region.

\subsection{Pseudo 3-D Grid Tomography}

[30] We invert for the shear velocity $\left(V_{s}\right)$ distribution across the study region at $1^{\circ}$ intervals. In Figure 9, we show the pseudo 3-D tomographic images at three depths corresponding to the top sedimentary layer and upper crust $(5 \mathrm{~km})$, the lower crust $(25 \mathrm{~km})$, and the uppermost mantle
$(50 \mathrm{~km})$. Three E-W and and three N-S vertical cross sections are shown in Figure 10.

[31] At $5 \mathrm{~km}$ depth, there are a number of prominent low $V_{s}$ anomalies. The most pronounced are on the western side of the continent, including the Cascadia fore arc (the Georgia-Pudget-Wallamette basin of southwestern British Columbia, western Washington, and central western Oregon), the Rocky Mountains of eastern Idaho, western Montana and Wyoming, and the Canadian Cordillera (Figures 1 and 9). These low $V_{s}$ anomalies in the northern U.S. have been documented previously using a similar tomography technique [Bensen et al., 2009; Shen et al., 2013]. The low $V_{s}$ signature of the Cordillera and Cascadia fore arc extends to the uppermost mantle. This is particularly evident when comparing the profile through the Canadian Cordillera to that through the western Canadian Shield (Figure 10, Profiles 1-1' versus 2-2'). We also find that the shallow low velocities beneath the southern Canadian and northern U.S. Cordillera extend north to the Yukon and Northwest Territories (Figure 9).

[32] For east Canada, the $V_{s}$ patterns are similar between the western and the eastern parts of the Canadian Shield, as shown by Profiles 2-2' and 3-3' in Figure 10, respectively. The most obvious shallow low $V_{s}$ anomaly is located beneath the southern Gulf of St. Lawrence sedimentary basin. Another 


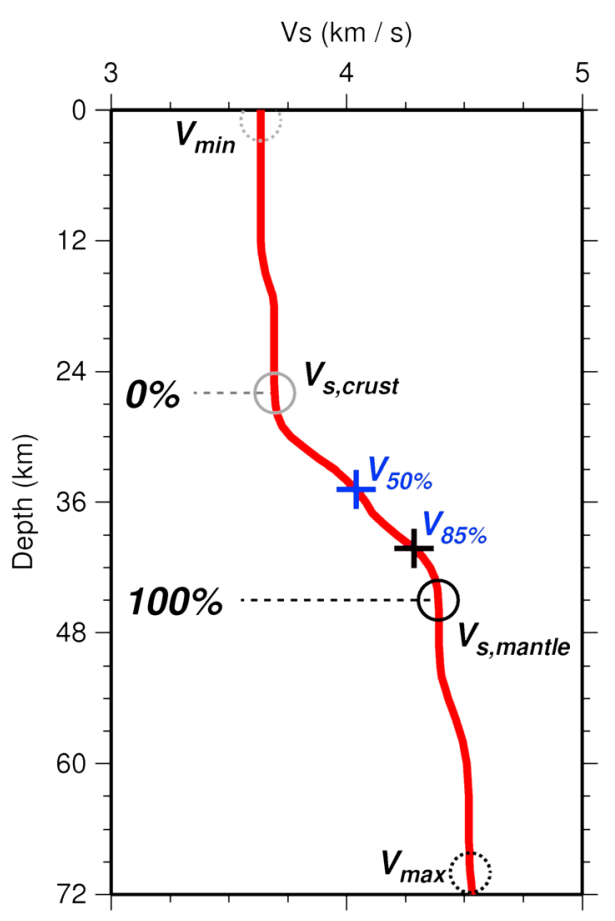

Figure 11. A schematic illustration on how the crust-mantle transition is characterized in this study. The lower crust shear velocity $\left(V_{s, \text { crust }}\right)$, located at the deepest depth before the crust-mantle transition, and the uppermost mantle shear velocities $\left(V_{s, \text { mantle }}\right)$, located at the shallowest depth after the crustmantle transition, define the $0 \%$ (gray circle) and 100\% (black circle) of the $V_{S}$ increase across the transition. Locations where the $V s$ increase reaches $50 \%$ and $85 \%$ are marked by blue and black crosses. Depth and shear velocity at the blue cross is inferred to be $Z_{50 \%}$ and $V_{50 \%}$. Depth and shear velocity at the black cross is inferred to be $Z_{85 \%}$ and $V_{85 \%}$.

low $V_{s}$ anomaly is revealed beneath Lake Superior where an ancient midcontinental rift system has been inferred from geological and geophysical data [Cannon et al., 1989]. However, there is no evidence of thick sediments because the rift system went through a stage of tectonic inversion at $1.1 \mathrm{Ga}$ with the central graben being uplifted by at least $5 \mathrm{~km}$ [Cannon et al., 1989]. Consequently, we suspect that the observed low $V_{s}$ anomaly beneath Lake Superior is not a manifestation of a thick sedimentary basin but instead may be an artifact arising from either a leaking effect from the top water layer or some unreliable dispersion measurements at periods of $<8 \mathrm{~s}$.

[33] From the three E-W profiles (Figure 10, A-A', B-B',

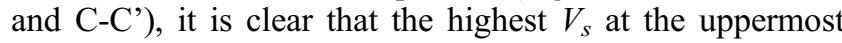
mantle depths is not directly associated with the center of the Canadian Shield. Instead, it corresponds to the stable Interior Platform and the outer rim of the Canadian Shield (900-1400 km in Profile A-A', 650-2050 km in Profile B-B', and 1000-2500 and 3250-3900 km in Profile C-C'). In general, the central part of the Shield appears to have $V_{s}$ consistently lower than that of the outer rim for all of the resolvable mantle depths.

[34] There are two interesting features in Profile C-C' that are distinct from the other profiles. One is the dome-like high $V_{s}$ anomaly in the middle and lower crust between $\sim 20$ and $40 \mathrm{~km}$ depths just to the west of Profile 2-2' (the region centered at the U.S.-Canada border between Montana and Manitoba, Figure 9b). The other is the generally broader vertical transition between lower crust and uppermost mantle, a feature we discuss in some detail in the next section.

\subsection{Crust-Mantle Transition}

[35] The crust-mantle transition (Moho) was first discovered in Europe as a subsurface velocity interface across which $V_{p}$ rapidly increases from $\sim 5.6$ to $>7.75 \mathrm{~km} / \mathrm{s}$ and $V_{s}$ from 3.27 to $4.18 \mathrm{~km} / \mathrm{s}$ [Mohorovicic, 1910]. Early studies concluded that the Moho generally corresponded to the depth at which the density of earth materials increases dramatically due to either compositional or phase changes [e.g., Adams and Williamson, 1923; Green and Ringwood, 1972; Ito and Kennedy, 1971]. However, as refraction seismology was undertaken in the different parts of the world, geophysicists realized that substantial variations exist in the Moho discontinuity's depth distribution, the magnitude of the velocity contrast, and its vertical extent [e.g., Cook et al., 2010; Mooney, 1987]. Furthermore, different remote sensing techniques (seismic refraction, seismic reflection, magnetotelluric measurements, etc.) often yield different Moho depths that may correspond to different physical aspects of the crust-mantle transition [e.g., Catchings and Mooney, 1991; Cook et al., 2010; Mooney and Brocher, 1987]. Consequently, an appropriate modifier is usually placed in front of the term "Moho" (such as refraction Moho, reflection Moho, or electric Moho) to indicate the specific geophysical technique employed in the survey [e.g., Cook et al., 2010].

[36] Globally, the Moho discontinuity is recognized as a large velocity increase from $V_{p} \sim 6.8-7.3 \mathrm{~km} / \mathrm{s}$ to $V_{p} \sim 8.2 \mathrm{~km} / \mathrm{s}$ [e.g., Mooney et al., 1998]. Using a typical $V_{p}-V_{s}$ relationship derived from laboratory data [Christensen, 1996], the corresponding $V_{s}$ jump is estimated to be $0.42-0.82 \mathrm{~km} / \mathrm{s}$ (from $V_{s}$ of $3.73-4.13$ to $4.55 \mathrm{~km} / \mathrm{s}$ ). With our new data, we are now able to provide some detail on the nature of this transition. As a descriptor of the Moho velocity transition, in Figure 10, we mark the two depths at which the $V_{s}$ has increased from a typical crustal velocity to a typical upper mantle velocity by $50 \%$ and $85 \%$ with the blue and red lines, respectively. The schematic diagram in Figure 11 illustrates how these two depths are determined. Specifically, at each grid point we first identify the lower crust shear velocity $\left(V_{s, \text { crust }}\right)$ and the uppermost mantle velocity $\left(V_{s \text {,mantle }}\right)$ by searching downward and upward, respectively, from the top $\left(V_{\min }\right)$ and bottom $\left(V_{\max }\right)$ of the corresponding $V_{s}$ profile (Figure 11). The $V_{s \text {,crust }}$ is defined at the deepest depth at which the shear velocity increase is less than $60 \%$ of the difference between $V_{\min }$ and $V_{\max }$ and the vertical velocity gradient is less than $0.025 \mathrm{~km} / \mathrm{s}$ (i.e., $0.1 \mathrm{~km} / \mathrm{s} V_{s}$ increase over a $4 \mathrm{~km}$ interval). Similarly, the $V_{s \text {,mantle }}$ is defined at the shallowest depth at which the shear velocity increase is at least $40 \%$ of the difference between $V_{\min }$ and $V_{\max }$ and the vertical velocity gradient is less than $0.025 \mathrm{~km} / \mathrm{s}$. The $V_{s}$ increase at a given level is defined as

$$
V_{r}=V_{s, \text { crust }}+r\left(V_{s, \text { mantle }}-V_{s, \text { crust }}\right)
$$

where $r$ is the percentage of $V_{s}$ increase (e.g., $50 \%$ or $85 \%$ ).

[37] In Figure 12, the depth range corresponding to this $50 \%-85 \% V_{s}$ increase, hereafter referred to as $\mathrm{d} Z_{50 \%-85 \%}$, is colored in gray. Most of the large velocity gradients occur 

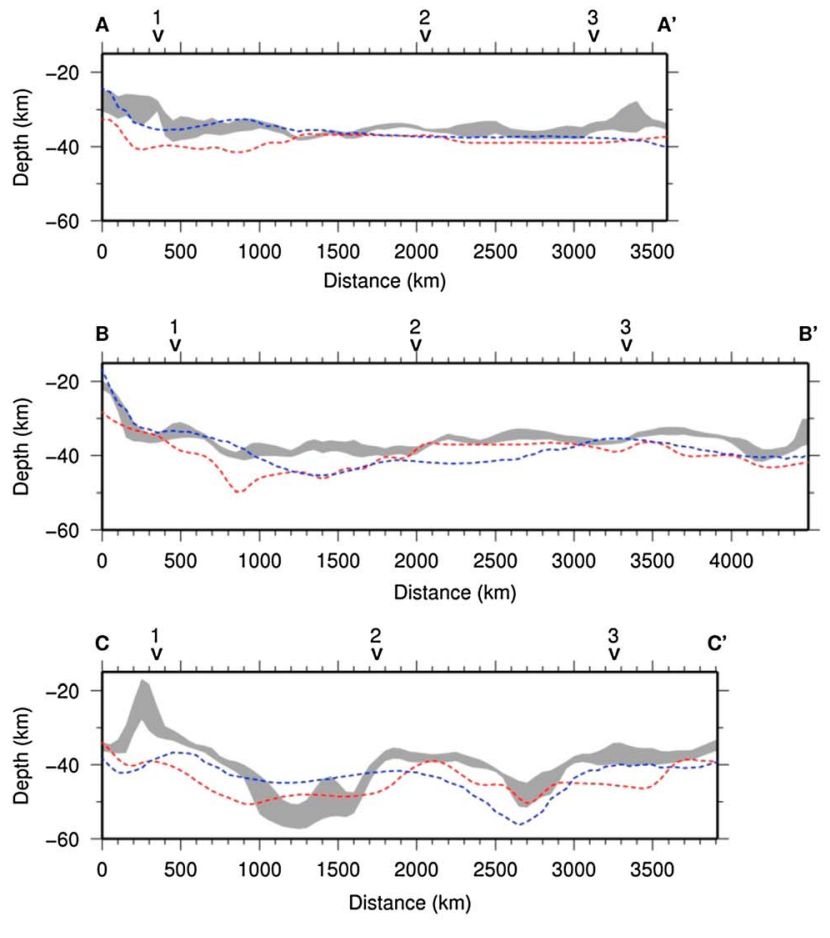

Crust-mantle transition (this study)
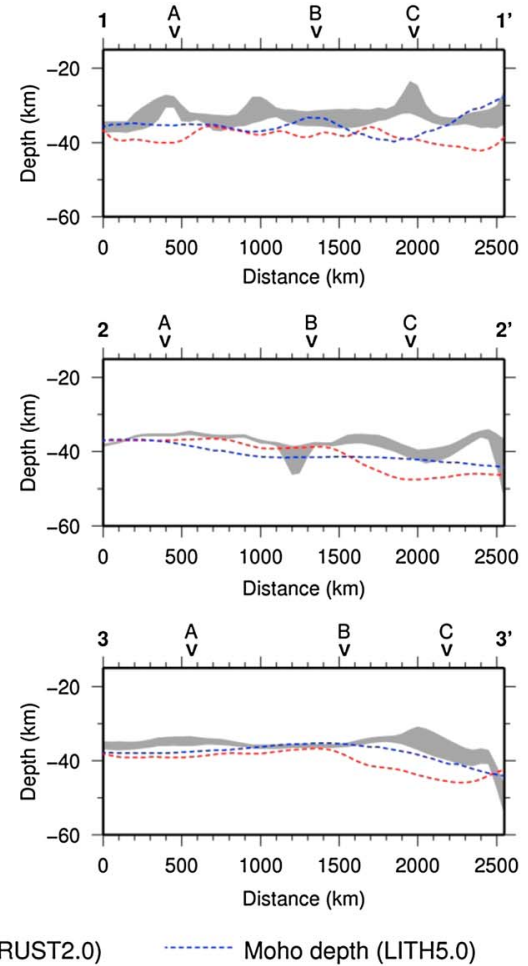

Figure 12. Cross sections showing the distribution of crust-mantle transition delineated from ambient noise tomography results (gray zone). Locations of the Moho discontinuity reported in the CRUST2.0 and LITH5.0 models are plotted in dashed red and blue lines, respectively, for comparison.

where $V_{s}$ jumps from $\leq 3.8 \mathrm{~km} / \mathrm{s}$ to $\geq 4.2 \mathrm{~km} / \mathrm{s}$ (Figure 10 ). However, there are exceptions where the downward velocity increase is gradual rather than abrupt. Given the varying thickness of the velocity increase from crust to uppermost mantle, the depth of a specific $V_{s}$ or an abrupt velocity jump (which is the common definition of a "refraction Moho," [e.g., Steinhart, 1967]) is a limited characterization of the crust-mantle transition. Similarly, the reflection Moho and electric Moho, which have been defined as "the deepest, high-amplitude, laterally extensive reflection or group of reflections" and "a step change in electrical conductivity" present in the vicinity of the corresponding refraction Moho, respectively [e.g., Cook et al., 2010; Jones and Ferguson, 2001; Klemperer et al., 1986], cannot well serve the purpose in some areas either.

[38] The appropriate definition of the "Moho" depends on the application. While the ambient seismic noise dispersion measurement is not the ideal tool for pinpointing the location of a seismic reflector such as the Moho, it is capable of distinguishing a sharp velocity discontinuity from a gradual one. This is supported by our analysis of modeling uncertainty versus depth (Figure S4). Although the depth uncertainty varies significantly across Canada, it is adequate for the proposed purpose of this study (i.e., $<5 \mathrm{~km}$ in most cases). The unique advantage of ambient seismic noise dispersion measurements for distinguishing the sharpness of Moho discontinuity enables us to examine the crust-mantle transition from a novel perspective. For places where the $V_{s}$ increase is gradual, a gradational transition between crustal and mantle properties and probably compositions is implied. We note, however, that it is not yet possible to determine whether the gradational layer is an intercalated mixture of crustal and mantle rocks or another mixed structure.

[39] As a general measure appropriate for many applications, including isostasy calculations, we propose a more comprehensive method of characterizing the crust-mantle transition. In Figure 13, the depth contours corresponding to $V_{s}$ increases of $50 \%$ and $85 \%$ from lower crust to uppermost mantle are plotted along with the corresponding velocities, $V_{50 \%}$ and $V_{85 \%}$ and their differences. Although it is convenient to identify the depth contour of $V_{85 \%}$ (i.e., $Z_{85 \%}$ ) as a proxy for the "ambient noise" Moho, it is important to realize that the abruptness of the crust-mantle transition is clearly nonuniform across the continent. Most areas beneath which a relatively sharp Moho discontinuity (i.e., $\mathrm{d} Z_{50 \%-85 \%}<2 \mathrm{~km}$ ) is inferred lie beneath the Canadian Shield (Figure 13c). For other regions, using a single Moho depth to define the crust-mantle transition is probably inappropriate.

[40] To first order, the depth distribution of the $85 \%$ crustmantle $V_{s}$ increase (i.e., $Z_{85 \%}$, Figure $13 \mathrm{~b}$ ) is similar to that presented by Bensen et al. [2009] and Cook et al. [2010] for regions south and north of the Canada-U.S. border, respectively. Our confidence in the results is reinforced by comparing our results at 133 grid nodes in the western U.S. $\left(43^{\circ} \mathrm{N}-49^{\circ} \mathrm{N}, 120^{\circ} \mathrm{W}-102^{\circ} \mathrm{W}\right)$ with the crustal models derived from joint inversion of ambient seismic noise dispersion measurements and receiver functions [Shen et al., 2013]. More than $88 \%$ of the $Z_{85 \%}$ values fall within $2 \mathrm{~km}$ from the reported ranges of Moho depth, and the difference never exceeds $4.5 \mathrm{~km}$.

[41] Relatively thick crust is found surrounding the Canadian Shield, whereas thin crust is associated with active deformation 

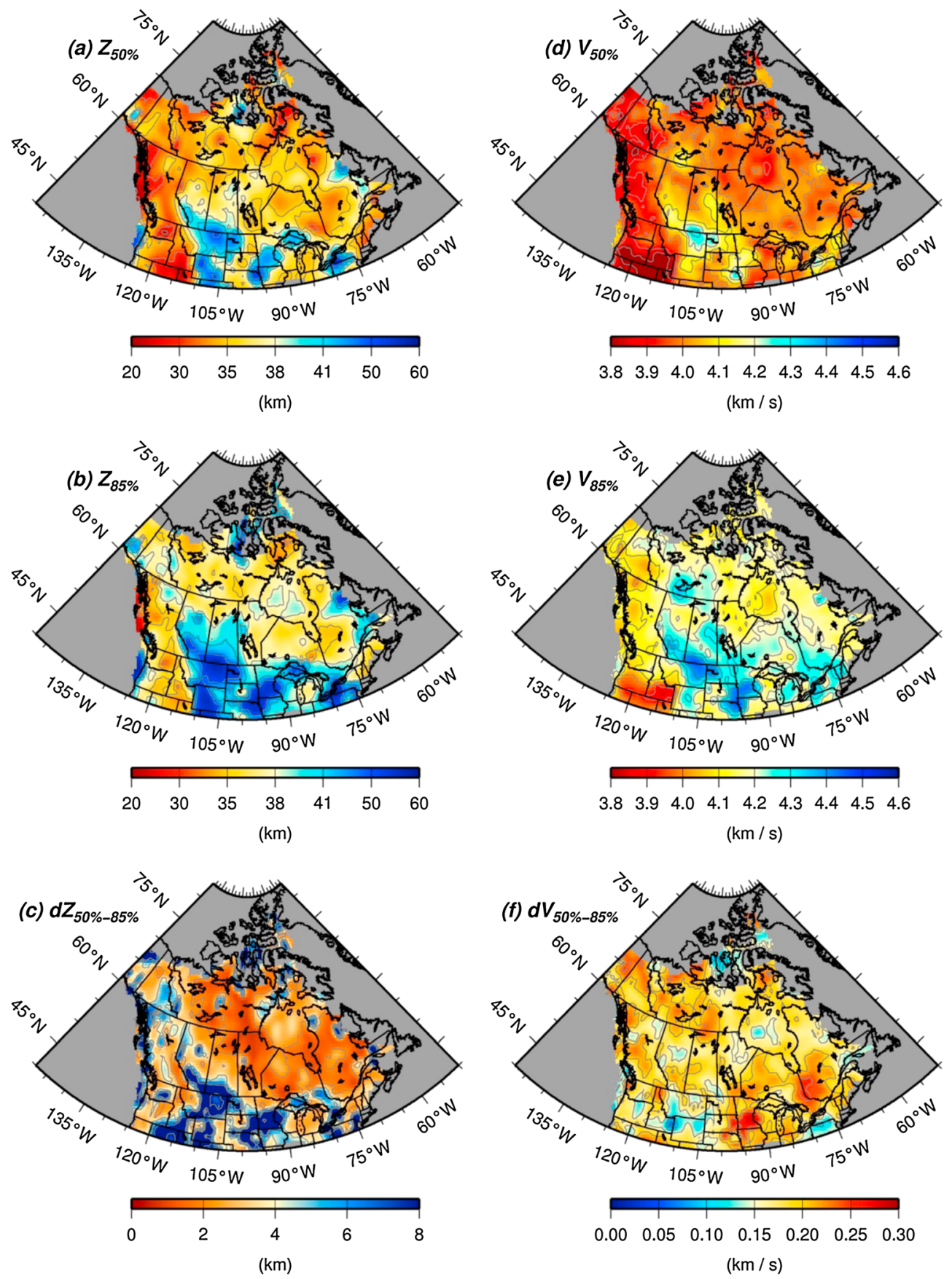

Figure 13. Physical properties of the crust-mantle transition beneath Canada and the adjacent regions. (a) Depth contours corresponding to 50\% shear velocity increase from crust to upper mantle. (b) Depth contours corresponding to $85 \%$ shear velocity increase from crust to upper mantle. (c) Thickness of the crust-mantle transition, which is the depth difference between Figures 13a and 13b. (d) Shear velocity at which the amount of increase is $50 \%$ from crust to upper mantle. (e) Similar to Figure $13 \mathrm{~d}$ but the amount of increase is $85 \%$. (f) Amount of shear velocity contrast across the crust-mantle transition, defined as the difference between Figures 13d and 13e.

such as that in the Cordillera and Cascadia. Overall, the crustal thickness beneath most of the Canadian craton is in the range of $35-41 \mathrm{~km}$.

[42] The Moho $V_{s}$, as represented by $V_{50 \%}$ and $V_{85 \%}$, shows a clear difference between the Cordillera and the continental interior (Figures $13 \mathrm{~d}$ and $13 \mathrm{e}$ ). Relatively low $V_{85 \%}$ (i.e., $\leq 4.1 \mathrm{~km} / \mathrm{s}$ ) is observed beneath the entire western orogenic belt including the Canadian Cordillera, the Columbia plateau, and the Cascadia fore arc. In contrast, most of the Canadian craton and central U.S. (e.g., northern Central Lowlands and Great Plains) are associated with relatively high Moho $V_{s}$. One exception is the central Hudson Bay Platform where the corresponding $V_{85 \%}$ is obviously lower. The relatively low crustal velocity beneath the Hudson Bay was also documented 


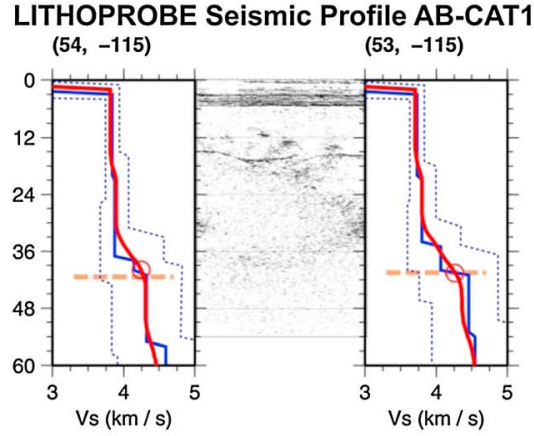

LITHOPROBE Seismic Profile GL-C $(48,-91)$

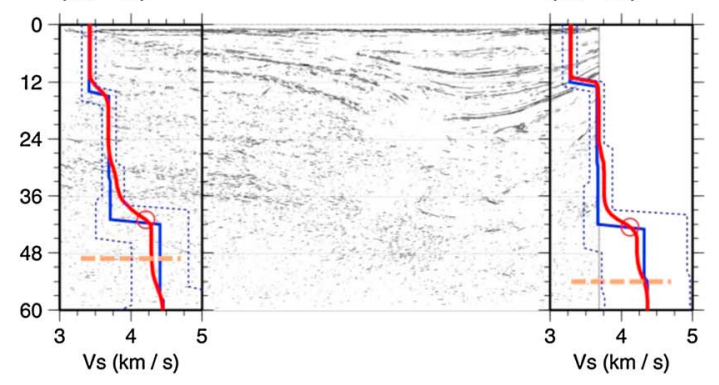

THOT-S1a $(55,-107)$

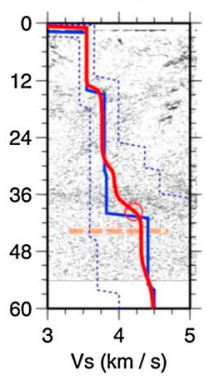

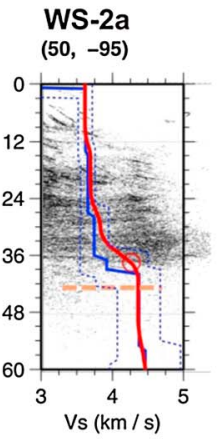

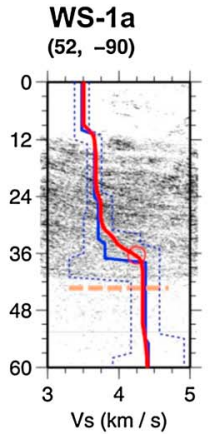

LITHOPROBE Seismic Profile GL-A

$(49,-87)$

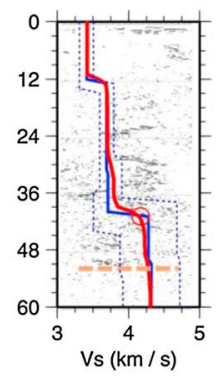

$(48,-87)$

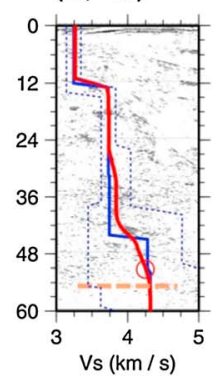

$(46,-88)$

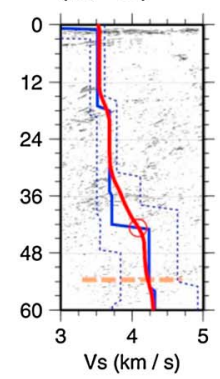

Figure 14. Comparison of Lithoprobe seismic reflection profiles and the shear velocity profiles of our tomography inversion at 10 selected grid nodes. The original Lithoprobe transect identifier is shown at the top of each reflection profile with the geographic coordinates of each grid node. The thick red and blue lines correspond to the weighted average and best fitting models, respectively. Red circles mark the location of ambient noise Moho which is defined as the location where shear velocity increases by $85 \%$ from lower crust to upper mantle. Dashed orange lines mark the Moho depths in the LITH5.0 model that are primarily derived from Lithoprobe data. Thin blue lines mark the model uncertainty as determined from forward modeling. Geographic locations of shear velocity profiles are marked in Figure 9c.

in a previous study using a regional data set of ambient seismic noise [Pawlak et al., 2010].

[43] For the cratonic region, an overall correlation amongst crustal thickness, Moho $V_{s}$, and the thickness of the crustmantle transition can be recognized (Figure 13). As the crust thickens from the center of the Canadian Shield outward, the corresponding $V_{85 \%}$ and $\mathrm{d} Z_{50 \%-85 \%}$ increase as well, except near Hudson Bay where the $V_{85 \%}$ appears to be the lowest. Such correlation also is not evident for the Cordillera, either. While the Cordillera has a thinner crust and a lower $V_{85 \%}$ than the craton, the thickness of the crust-mantle transition is intermediate, varying between 2 and $5 \mathrm{~km}$.

\subsection{Large Velocity Gradients in Midcrust}

[44] Our tomographic results show the existence of large vertical $V_{s}$ gradients within the midcrust in some areas. Examples of such large gradients can be seen in the six cross sections across different parts of the continent in Figure 10 and the $V_{s}$ profiles shown in Figure 14. The geographic distribution of large velocity gradients is not uniform across Canada, however, and their depth distribution varies from one region to another. In most cases, the $V_{s}$ increase is between 0.2 and $0.5 \mathrm{~km} / \mathrm{s}$ with larger gradients generally corresponding to lower $V_{s}$ in the upper crust.

[45] The most prominent midcrust $V_{s}$ gradient is beneath the Cordillera, and best illustrated in Figure 10 (Profile 1-1'). Its depth increases to the south. The section just south of Profile A-A' has a large midcrust $V_{s}$ gradient at $\sim 5 \mathrm{~km}$ depth. It is located at $\sim 9$ and $11 \mathrm{~km}$ beneath the sections around Profile B-B' and to the south of C-C', respectively. In addition, the large midcrust $V_{s}$ gradient is not continuous across the entire Cordillera. Several gaps, each a few hundreds of kilometers long, exist between sections in which the large midcrust $V_{s}$ gradient is clear.

[46] Another region in which a prominent midcrust $V_{s}$ gradient is observed is the craton beneath part of the Canadian Shield. The western half of the Superior Province (between 2300 and $3100 \mathrm{~km}$ in Profile C-C', Figure 10; also profiles GL-A and GL-C, Figure 14) shows a clear $V_{s}$ jump at a depth of $\sim 12 \mathrm{~km}$. This large $V_{s}$ jump defines the lower boundary of the upper crust.

[47] A large midcrust $V_{s}$ gradient also exists beneath the easternmost section of Profile B-B' where the Canadian Shield meets the Appalachian belt (Figure 10). However, it is not common in the Appalachians because similar $V_{s}$ jumps are not observed beneath the easternmost end of the Profile C-C'. Unfortunately, limited data resolution prevents us from obtaining a high-resolution velocity image for this part of the continent. Further investigation with a denser regional seismograph network in the region is needed.

\section{Quantitative Comparison With Previous Models}

[48] In this section, we make quantitative comparisons of our results with previous models in the literature that were derived from different data sets. By systematically examining 
and characterizing the different models' similarities and differences, our purpose is to provide an objective assessment of our model in terms of regional variation and data resolution.

\subsection{Lithoprobe Transects}

[49] In Figure 14, we show $10 V_{s}$ profiles from our results and compare them with nearby seismic reflection profiles from the Lithoprobe program [Clowes et al., 1984; Cook, $2002]$ and other studies. The map locations of the $10 V_{s}$ profiles are marked in Figure 9c (red crosses). These examples are chosen either because they show a gradual crust-mantle transition or because the location of the largest velocity gradient is inconsistent with the previously reported Moho depths. Specifically, we compare five $V_{s}$ profiles in the vicinity of Profile B-B' with Lithoprobe transects AB-CAT1 (at a distance of $\sim 1200 \mathrm{~km}$; Figure 10), transect THOT-S1a $(\sim 1500 \mathrm{~km}), \mathrm{WS}-2 \mathrm{a}(\sim 2300 \mathrm{~km}), \mathrm{WS}-1 \mathrm{a}(\sim 2600 \mathrm{~km})$, and another five $V_{s}$ profiles in the vicinity of Profile C-C' with transects GL-C $(\sim 2400 \mathrm{~km})$ and GL-A $(\sim 2700 \mathrm{~km})$.

[50] The base of deep crustal subhorizontal reflectivity is typically close to our inferred Moho but there are some exceptions. For transect AB-CAT1 passing through the Interior Platform in central Alberta, the bottom part of the zone containing strong seismic reflectors was used in previous studies to define the "reflection" Moho at a depth of $40 \mathrm{~km}$ [Perry et al., 2002]. In our results, it corresponds to a velocity increase over a $7 \mathrm{~km}$ interval between $33 \mathrm{~km}$ and $40 \mathrm{~km}$ $\left(V_{s}\right.$ profiles at $54^{\circ} \mathrm{N}, 115^{\circ} \mathrm{W}$ and $53^{\circ} \mathrm{N}, 115^{\circ} \mathrm{W}$, Figure 14 ). Similar situations are observed for transect THOT-S1a through the Western Canadian Sedimentary Basin $\left(55^{\circ} \mathrm{N}, 107^{\circ} \mathrm{W}\right)$ and transect WS-2a through the western part of the Superior Craton $\left(50^{\circ} \mathrm{N}, 95^{\circ} \mathrm{W}\right)$, except that the Moho discontinuity in the LITH5.0 model is $\sim 4 \mathrm{~km}$ deeper. Near the northern end of transect WS-1a in the central Superior Craton $\left(52^{\circ} \mathrm{N}\right.$, $\left.90^{\circ} \mathrm{W}\right)$, the discrepancies among our $V_{s}$ profile, the seismic reflection image, and the LITH5.0 model are apparent as the bottom of the strong seismic reflector zone (i.e., the reflection Moho) is located between the largest velocity gradient at $32-38 \mathrm{~km}$ and the Moho depth in the LITH5.0 model (i.e., the refraction Moho) at $43 \mathrm{~km}$.

[51] One of the biggest inconsistencies between the crustmantle velocity gradients found in our analysis and the Moho depths in the LITH5.0 model is observed in the vicinity of Lake Superior, where transects GL-A and GL-C are located. Taking transect GL-C as an example, the $V_{s}$ profile near the northwestern end $\left(48^{\circ} \mathrm{N}, 91^{\circ} \mathrm{W}\right)$ shows a large velocity gradient between 36 and $41 \mathrm{~km}$ near the bottom of the zone of strong seismic reflectors. In comparison, the Moho depth is reported to be $49 \mathrm{~km}$ in the LITH5.0 model, below which another gradual $V_{s}$ increase is observed. Similarly, the $V_{s}$ profile near the southeastern end of transect GL-C $\left(47^{\circ} \mathrm{N}, 89^{\circ} \mathrm{W}\right)$ exhibits a big velocity jump at $38-43 \mathrm{~km}$ that approximately coincides with the bottom of the strong seismic reflectors (Figure 14). A much smaller velocity increase is found at $\sim 54 \mathrm{~km}$ depth where the LITH5.0 model defines the Moho discontinuity, although evidence from the seismic reflection image is unclear.

[52] For the three locations near transect GL-A passing through the center of Lake Superior $\left(49^{\circ} \mathrm{N}, 87^{\circ} \mathrm{W} ; 48^{\circ} \mathrm{N}\right.$, $87^{\circ} \mathrm{W} ; 46^{\circ} \mathrm{N}, 88^{\circ} \mathrm{W}$ ), the largest velocity gradients all correspond to strong seismic reflectors within rather than at the bottom of the reflector zones. Our $V_{s}$ profiles show that the velocity begins to increase gradually at the depths where strong seismic reflectors become apparent, and the increase extends down to the bottom of the reflector zone where the Moho depth is defined in the LITH5.0 model.

\subsection{Ambient Noise Moho Versus Reflection and Refraction Mohos}

[53] In a global review of seismic reflection/refraction studies of the continental lithosphere, Mooney and Brocher [1987] pointed out that the lower crust appears to consist of laminated high and low velocity layers with typical thicknesses of 100-200 m, making it much more reflective than either the upper crust or the uppermost mantle. Therefore, the Moho depth determined from seismic reflection data may involve a clear reflector, but often is defined as the bottom of the reflective layers that generally coincides with the refraction Moho to within a few kilometers. For places with complex lower crustal and/or uppermost mantle structures, however, constructive and destructive interferences among seismic signals from different structures may lead to ambiguous interpretations of the Moho depths [e.g., Catchings and Mooney, 1991; Cook, 2002]. The occasionally significant discrepancies between refraction and reflection Moho depths of as much as $10 \mathrm{~km}$ are well documented in the results of the Lithoprobe project [Cook et al., 2010].

[54] It is important to recognize that the reflection and refraction Mohos are usually determined from $V_{p}$ and $P$ wave impedance contrast, whereas the ambient noise Moho is based on the $V_{s}$ distribution. Shear and compressional wave interface depths are expected to be similar but there is a possibility of differences. A direct comparison between the ambient noise Moho relief determined in this study (Figures 12 and 13) and the Moho relief inferred from Lithoprobe reflection and refraction data [Cook et al., 2010, Figures 2 and 3] suggests that all three tend to imply that thin and thick crust is located beneath the Cordillera and craton, respectively. However, for a large portion of the cratonic region, the refraction Moho usually is the deepest, followed by the reflection Moho, and the ambient noise Moho usually is the shallowest. The difference is generally $<5 \mathrm{~km}$. When a significant discrepancy exists between the reflection and refraction Moho, we notice that the ambient noise Moho tends to be more consistent with the one that is better constrained. For example, the local variation in the ambient noise Moho depth beneath central northern Alberta (Figures 13a and $13 \mathrm{~b}$ ) is visible on the refraction Moho, as constrained by several Lithoprobe refraction transects, but not clear on the reflection Moho [Cook et al., 2010]. Similarly, the locally shallower ambient noise Moho beneath the Ontario-Quebec border is more consistent with the reflection Moho that incorporated constraints from a number of reflection profiles but not with the refraction Moho.

[55] There are exceptions in which the three Moho depths do not necessarily follow the downward order of ambient noise, reflection, then refraction. One such example is in central Quebec (e.g., $\left.53^{\circ} \mathrm{N}, 74^{\circ} \mathrm{W}\right)$ where the ambient noise Moho is the shallowest $\left(Z_{50 \%}\right.$ and $Z_{85 \%}$ at 32 and $36 \mathrm{~km}$, respectively, Figure 13) followed by the refraction Moho $(\sim 39 \mathrm{~km})$ and the reflection Moho $(\sim 45 \mathrm{~km})$. Another similar example is in southern Quebec near the Canada-U.S. border (e.g., $45^{\circ} \mathrm{N}, 73^{\circ} \mathrm{W}$ ). Once again, the ambient noise Moho is the shallowest ( $Z_{50 \%}$ and $Z_{85 \%}$ at 35 and $38 \mathrm{~km}$, respectively), 


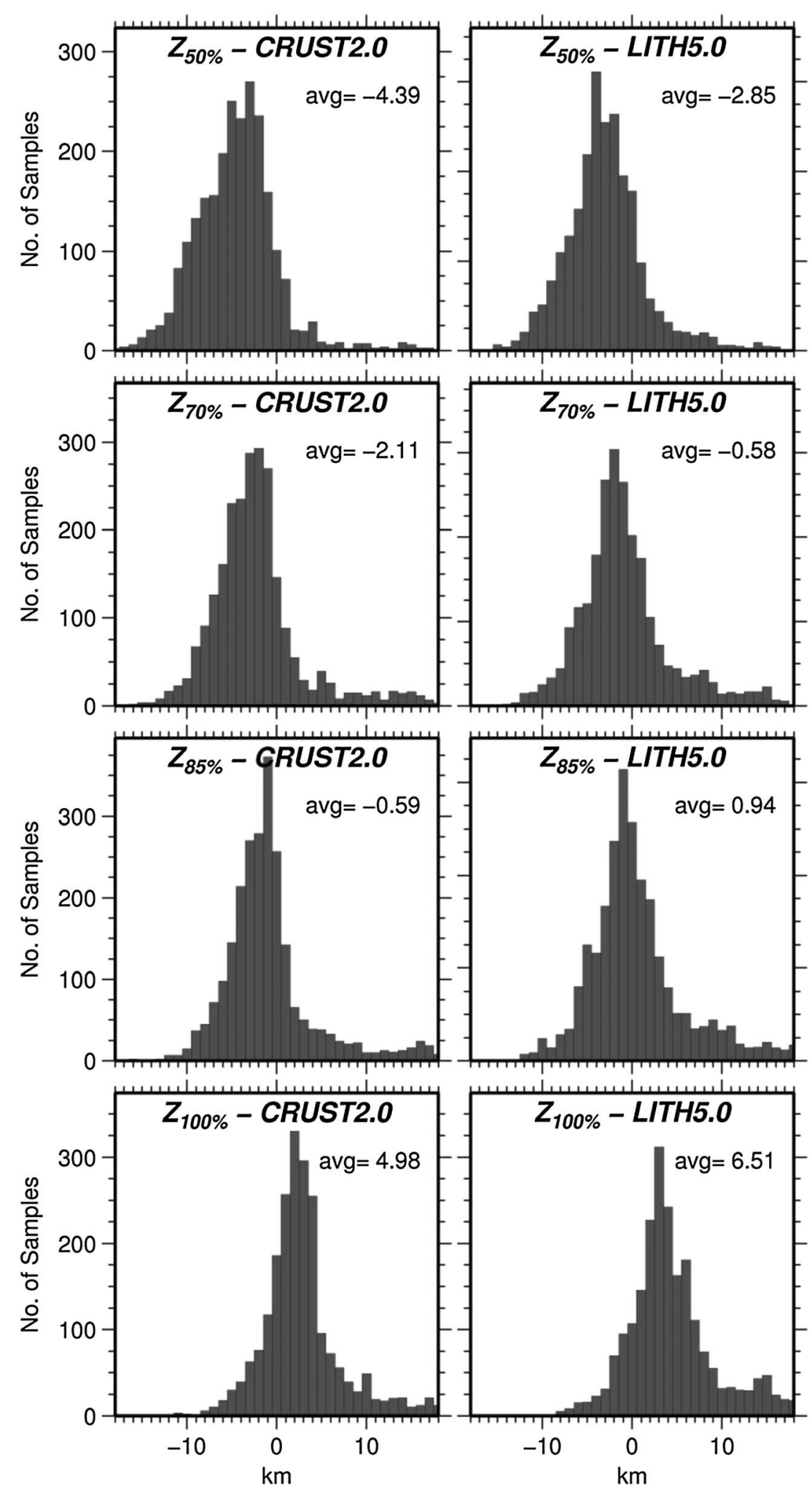

Figure 15. Histograms showing the depth difference between the crustal model determined in this study and two previous models, (left) CRUST2.0 and (right) LITH5.0. $Z_{50 \%}, Z_{75 \%}, Z_{85 \%}$, and $Z_{100 \%}$ correspond to the depths where the increase of shear velocity is $50 \%, 75 \%, 85 \%$, and $100 \%$ from the lower crust to the uppermost mantle. The mean value (avg) of all samples is given near the top right corner of each plot. We use the $Z_{85 \%}$ as a proxy for the ambient noise Moho because it yields the least overall difference with respect to both CRUST2.0 and LITH5.0 models. 


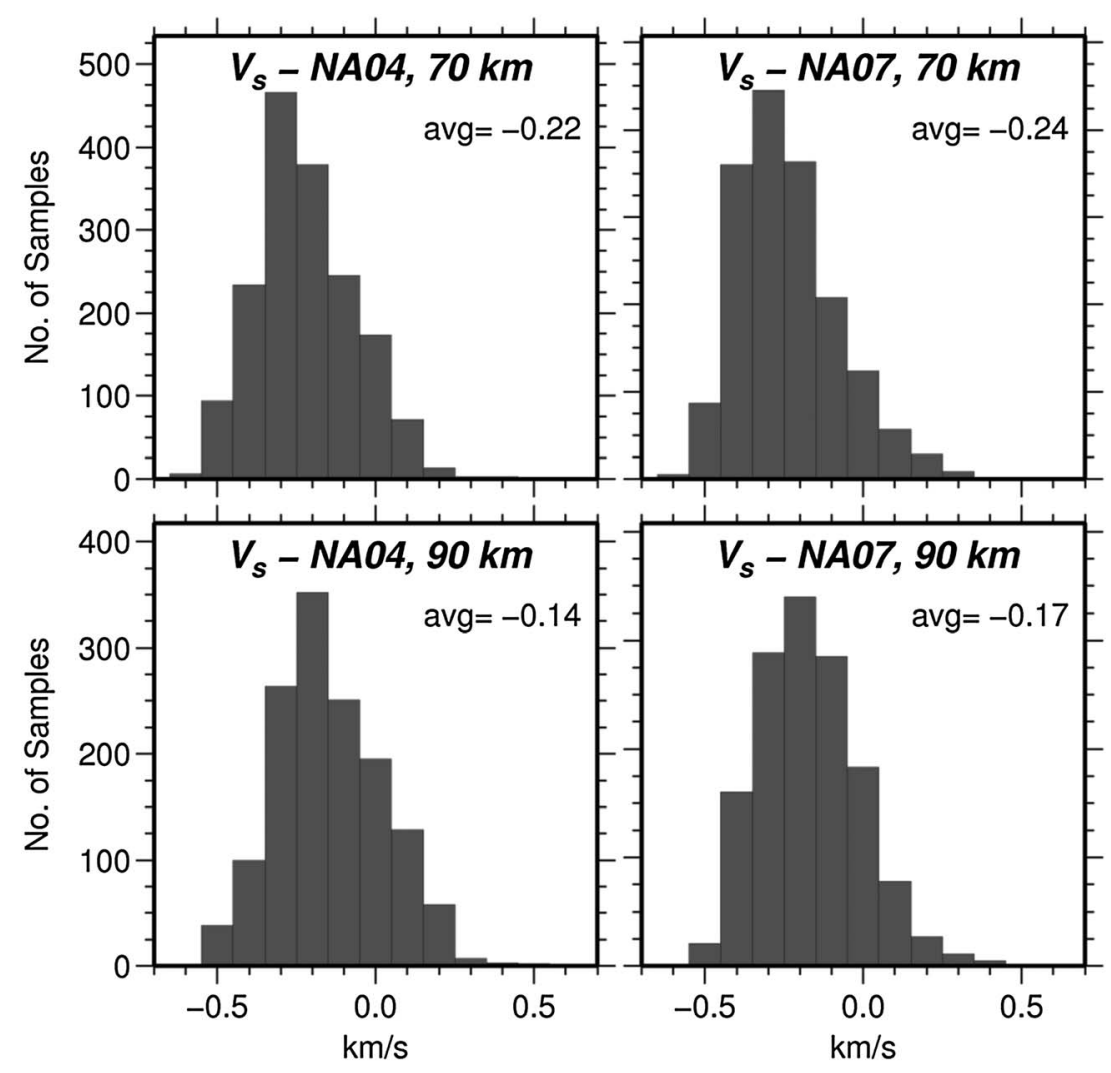

Figure 16. Histograms showing the velocity difference between the velocity model determined in this study and two previous tomography models based on earthquake data, (left) NA04 and (right) NA07. The top and bottom correspond to the depth of 70 and $90 \mathrm{~km}$, respectively. Overall, our results are slightly slower than those reported in previous models, as indicated by the mean value (avg) given near the top right corner of each plot. This systematic difference is likely due to the effect of radial anisotropy in the upper mantle. See text for more details.

followed by the refraction Moho at $\sim 42 \mathrm{~km}$ and the reflection Moho at $\sim 45 \mathrm{~km}$. Notice that the numbers of available Lithoprobe transects, refraction or reflection, for both regions are very few, meaning that the inferred reflection or refraction Moho depths are less constrained.

[56] Further detailed local studies will be required to thoroughly investigate the relationships among different Moho depths and their physical relevance to the crust-mantle transition. In this paper, we provide only an initial discussion on this subject. In theory, different approaches are sensitive to different aspects of the velocity structure. While seismic reflection is best at illuminating velocity interfaces with large impedance contrast, seismic refraction is generally sensitive to the variation of velocity at depth. The difference may result in the refraction Moho being systematically deeper than the reflection Moho, especially if the bottom of the lower crust is not strongly reflective [Catchings and Mooney, 1991]. As we define the ambient noise Moho based on the sharpness of $V_{s}$ variation across the crust-mantle transition, our result should be more sensitive to the overall composition change than to either the impedance contrast or the velocity of the bottom layer of the lower crust.

[57] A recent study of the physical properties of the Paleozoic Cabo Ortegal Complex of NW Spain suggests that the crust-mantle transition is a gradation from felsic gneisses to ultramafic rocks with eclogites and mafic granulties in between [Brown et al., 2009]. In such a scenario, the velocity Moho (reflection or refraction) actually corresponds to the boundary between the gneisses and the eclogite at a shallower depth, whereas the petrological Moho is located between the mafic granulites and ultramafic peridotites at a greater depth. The fact that the ambient noise Moho is often located at shallower depths than either the reflection or the refraction Moho seems to imply that the deepest structure of the crust-mantle transition does not necessarily correspond to the largest velocity jump. It may be that the top of our Moho gradient layer marks the beginning of the gneisseclogite transition and the base represents the downward transition to ultramafic peridotite.

\subsection{Previous Crustal and Tomography Models}

[58] Given the large number of previous studies of the seismic velocity structures of North America, it is impractical to compare our results with all the models described in the literature. There are also important issues to be considered before a meaningful comparison can be conducted, including the availability of model parameters, the scale and geographic coverage of each model, and the model resolution. However, to facilitate quantitative comparison of our model with other models of interest, we have compiled a digital 
version of Figure 13 listing the physical parameters of the inferred ambient noise Moho and an ASCII table showing our tomography results (available online as supporting information). For demonstration purposes, we conduct comparisons with two crustal models cited frequently in this paper, CRUST2.0 [Bassin et al., 2000] and LITH5.0 [Perry et al., 2002], and two recent North American tomography models, NA04 [van der Lee and Frederiksen, 2005] and NA07 [Bedle and van der Lee, 2009], available in digital form at the IRIS website.

[59] In Figure 12, we plot the Moho depths of the LITH5.0 [Perry et al., 2002] and CRUST2.0 [Bassin et al., 2000] models as dashed blue and red lines, respectively, to summarize previous observations. Depending on the percentage of $V_{s}$ increase defined in equation 1 , the average depth difference between our model and the two previous crustal models may vary from $-4.4 \mathrm{~km}\left(Z_{50 \%}\right.$-CRUST2.0) to $6.5 \mathrm{~km}\left(Z_{100 \%}-\right.$ LITH5.0), as shown by the histograms in Figure 15.

[60] Taking the $Z_{85 \%}$ as a proxy for the ambient noise Moho, our result is on average $0.6 \mathrm{~km}$ shallower than that of CRUST2.0 model. This difference is negligible given the model uncertainty in our inversion. The corresponding standard deviation is $5.8 \mathrm{~km}$. With respect to the LITH5.0 model, our model is on average $0.9 \mathrm{~km}$ deeper with a slightly larger standard deviation of $6.2 \mathrm{~km}$. We notice that many of the high standard deviations correspond to nodes at which the discrepancy between the CRUST2.0 and LITH5.0 models exceeds $10 \mathrm{~km}$. In other words, we expect a large discrepancy with respect to one or the other of the two models at these nodes. We list the corresponding Moho depths of the CRUST2.0 and LITH5.0 models in the supporting information to allow comparison at specific nodes/regions.

[61] Both the NA04 and NA07 models provide seismic velocity distributions for the entire upper mantle from $70 \mathrm{~km}$ to $670 \mathrm{~km}$ at interval of $20 \mathrm{~km}$, whereas our tomography results only have adequate resolution for comparatively shallow depths $(<100 \mathrm{~km})$. Therefore, only the top two layers of the NA04 and NA07 models (i.e., $70 \mathrm{~km}$ and $90 \mathrm{~km}$ ) are used in the comparison.

[62] At a depth of $70 \mathrm{~km}$, our model is on average 0.21 and $0.24 \mathrm{~km} / \mathrm{s}$ slower than the NA04 and NA07 models, respectively (Figure 16). The corresponding standard deviation of the velocity difference is $0.16 \mathrm{~km} / \mathrm{s}$ for both. Most of the nodes with large discrepancies (i.e., larger than one standard deviation) are located near the boundary of our model where the raypath coverage is not optimal. However, there are places where the difference is large and yet the resolution length is reasonable (e.g., central Canada north of $\sim 60^{\circ} \mathrm{N}$ ). Further investigation of these places using an independent data set and/or methodology should be undertaken.

[63] Similarly, for the $90 \mathrm{~km}$ depth, the average $V_{s}$ of our model is 0.14 and $0.17 \mathrm{~km} / \mathrm{s}$ slower than that of NA04 and NA07 models, respectively (Figure 16). The standard deviation stays almost unchanged (0.17 for NA04 and 0.16 for NA07), and many of the nodes with $V_{s}$ differences exceeding one standard deviation are the same ones as identified at the $70 \mathrm{~km}$ depth. This suggests that the difference between our tomography model and those derived from earthquake data is probably systematic and strongly data dependent. Again, this systematic difference needs to be further examined, especially for applications that require accurate velocities for composition and temperature estimates.

\section{Implications and Discussion}

[64] Shear velocity is one of the fundamental physical properties characteristic of earth materials. It is strongly linked to composition and state such as temperature and in turn to the patterns of present deformation and evolutionary history of tectonic/geological structures. The 3-D velocity tomography is especially useful in delineating deep structures and assessing their tectonic implications. In this section, we discuss topics directly relevant to our data and seismological results. Other important subjects for which our data provide new constraints, such as the temperature variations in the lithosphere across different tectonic/geologic provinces and the density distribution within the crust and uppermost mantle, require additional analysis and will be addressed in a subsequent article.

\subsection{Surface Geology and Topography of the Crust- Mantle Transition}

[65] In general, the surface geology of Canada (south of $70^{\circ} \mathrm{N}$ ) can be divided into five components, namely, the Cascadia fore arc, the North America Cordillera, the sedimentary basins overlying the craton (i.e., the Interior Platform and the Hudson Bay Platform), the exposed craton (i.e., the Canadian Shield), and the Appalachian orogen [e.g., Wheeler et al., 1997]. Previous crustal models have indicated that the Cascadia fore arc and Cordillera are associated with relatively thin $(\sim 35 \mathrm{~km}$ and less) crust, whereas the crustal thickness in the stable craton region is 40-45 km [Bassin et al., 2000; Mooney et al., 1998; Perry et al., 2002]. The significant differences in the average elevation and Moho depth have been explained as the thermal isostasy buoyancy effect due to higher lithospheric temperatures in the Cordillera [e.g., Currie and Hyndman, 2006; Hyndman and Currie, 2011].

[66] While the average crustal thickness inferred from our tomography results is in good agreement with previous models, we notice that the Moho relief within each geological region, as manifest by the depth contours of $50 \%$ and $85 \% V_{s}$ increase from crust to uppermost mantle, is not as uniform as previously mapped (Figures 10-14). For example, the Moho depth beneath the Cordillera shows local variations that fluctuate between 25 and $38 \mathrm{~km}$ (e.g., Figure 12, Profile 1-1'). Locations with particularly shallow crust-mantle transition generally coincide with volcanic areas where the crustal structure may be affected by recent volcanic processes. The Moho topography may also be related to the mechanical strength/rigidity of the lithosphere, and the pattern of mantle flow [Currie and Hyndman, 2006]. It is beyond the scope of this study to determine the exact physics controlling the Moho topography, but our results suggest that the dominant process involves factors that vary locally on scales of $100-1000 \mathrm{~km}$.

[67] Even within the cratonic region, there are significant regional variations in the crustal thickness are observed (Figures 12 and 13). While the general trend of the Moho depth increases from north to south, there are clear local highs and lows along the E-W direction (Figures 12, Profiles A-A', B-B', and C-C', 13a, and 13b). Previous studies on the effective elastic thickness of the lithosphere also show significant variations for different parts of the craton [e.g., Burov et al., 1998; Flück et al., 2003; Hyndman et al., 2009; Mareschal et al., 2005; Wu, 1991]. Such variations have been attributed 
to the strong lateral variations in the thermal regime of the lithosphere [Flück et al., 2003; Hyndman et al., 2009; Wang and Mareschal, 1999], large-scale crustal heterogeneity [Burov et al., 1998; Guillou-Frottier et al., 1996], or both [Mareschal et al., 2005; Wu, 1991]. Our results suggest that the lateral variation of crustal structures, including the thickness, may also play a role in controlling the effective elastic thickness of the lithosphere.

\subsection{Sharpness of the Crust-Mantle Transition}

[68] The sharpness of a velocity interface can be characterized by two parameters: its thickness and the amount of velocity change. For the same velocity change, a sharp interface means that it is very thin with a large velocity jump, whereas a diffused one spans a finite depth range with a gradual velocity variation. Most previous studies using global crustal models, however, have not adequately addressed the sharpness of the crust-mantle transition. Our results provide systematic estimates of the thickness and corresponding $V_{s}$ increase of the crust-mantle transition for most of the North American continent north of $40^{\circ} \mathrm{N}$ that, in turn, could help constrain interpretations of the formation and subsequent tectonic evolution of the continental crust.

[69] It is interesting to point out that there is a slight anticorrelation between the crust-mantle transition thickness $\mathrm{d} Z_{50 \%-85 \%}$ and the amount of velocity change $\mathrm{d} V_{50 \%-85 \%}$ (Figures 13c and 13f). Overall, the Canadian Shield is associated with a relatively smaller $\mathrm{d} Z_{50 \%-85 \%}$ and a larger $\mathrm{d} V_{50 \%-85 \%}$. As the $\mathrm{d} Z_{50 \%-85 \%}$ increases from the Canadian Shield outward, the corresponding $\mathrm{d} V_{50 \%-85 \%}$ decreases accordingly, but the relationship is not linear. One exception is the American midwest region between $90^{\circ} \mathrm{W}$ and $100^{\circ} \mathrm{W}$ where both the $\mathrm{d} Z_{50 \%-85 \%}$ and $\mathrm{d} V_{50 \%-85 \%}$ are large.

[70] It has been suggested that the structural details associated with the crust-mantle transition may be too complex and varied for a single, universally applicable interpretation of the continental Moho discontinuity [Cook et al., 2010]. In fact, a comprehensive compilation of the "geophysical" Moho distribution from Lithoprobe data have concluded that the continental Moho discontinuity is not a simple boundary and may not always coincide with the petrological Moho [e.g., Cook et al., 2010; Moores, 1982], although a large portion of Canada remains unexplored by Lithoprobe-type transects. Our ambient noise tomography results confirm that the crust-mantle transition is characterized by a finite zone whose thickness and velocity contrast may vary from one geological/tectonic region to another.

[71] If we take the seismic velocity as a reasonable proxy for the density and composition of crustal materials [Christensen and Mooney, 1995], then the sharpness of the ambient noise Moho can be viewed as a first-order indicator of how much the position, geometry, and physical properties of the crustmantle transition have developed over the geological history. Further studies with high resolution at local and regional scales are obviously needed to better understand the geological and tectonic significance of the variations in the sharpness of the ambient noise Moho.

\subsection{Tectonic Significance of the Large Midcrust Velocity Gradients}

[72] The original discovery of a common midcrust velocity discontinuity, often called the Conrad discontinuity, was based on seismic signals refracted from a velocity interface located at a depth of $15-20 \mathrm{~km}$ with $V_{p}$ of $\sim 6.5 \mathrm{~km} / \mathrm{s}$ [Richter, 1958]. Although it was first interpreted to be the boundary between a granitic upper crust and a basaltic lower crust, later research indicated that such a simple interpretation could not explain the observed complexity [e.g., Fountain and Christensen, 1989]. Not only is the midcrust discontinuity far less frequently observed than the Moho, but the corresponding seismic velocities are often not those of typical granitic or basaltic compositions [Christensen and Mooney, 1995].

[73] One recent explanation for a midcrustal boundary was provided by Mazzotti and Hyndman [2002] based on the distribution of regional seismicity, heat flow measurements, geodetic data, and numerical modeling of the northern Cordillera region. They proposed that the lower crust is weak due to consistently high temperatures beneath the Cordillera and other current or recent back arcs. According to that model, there is ductile detachment in the middle to lower crust that allows substantial relative motion between the quasi rigid upper and the lowermost crust and upper mantle. We speculate that the large midcrust velocity gradients observed beneath the Cordillera, as described in section 3.4, are also related to such midcrustal detachment zones. The midcrust velocity contrast in this region probably represents a thermodynamically controlled interface that may have played an important role in the regional thick-skinned tectonics.

[74] For the large midcrust velocity gradient beneath part of the Canadian Shield (Figures 10, 13, and 14), the most straightforward interpretation would be a relict rheological boundary between the upper and lower crust formed at earlier times when temperatures were much higher. The corresponding velocity difference may be explained by a change of composition from an average mix of $45 \%$ granitic gneiss and $5 \%$ amphibolite at the upper crust depths to $15 \%$ granitic gneiss and 35\% amphibolite in the lower crust [Christensen and Mooney, 1995]. Depending on other possible factors such as the depth of the discontinuity and its sharpness, the exact compositional ratio may vary from one place to another.

\subsection{Possible Effect of Anisotropy}

[75] The velocity structures derived from our tomography inversion are assumed to be isotropic. This assumption is obviously simplistic for places where azimuthal anisotropy has been demonstrated previously, such as in Cascadia [Currie et al., 2004; Eakin et al., 2010; Rieger and Park, 2010], the Superior province [Darbyshire et al., 2007], and the Appalachians [Barruol et al., 1997; Levin et al., 1999]. Based on earthquake data, Yuan and Romanowicz [2010] estimate the amount of azimuthal anisotropy in the upper mantle beneath the North America craton to be of the order of $1 \%$.

[76] In a recent global earthquake surface wave dispersion study, Nettles and Dziewonski [2008] pointed out that the transverse component of shear velocity (i.e., $V_{\mathrm{SH}}$ ) is on average $2-6 \%$ faster than the radial component $\left(V_{\mathrm{SV}}\right)$ at the uppermost mantle depths beneath Canada. Using the dense U.S. Transportable Array ambient noise data, Moschetti et al. [2010b] concluded that the mean amplitude of radial anisotropy in the lower crust and upper mantle beneath the western U.S. are 3.6\% and 5.3\%, respectively. Because both NA04 and NA07 models are derived from inversion of shear 
and Rayleigh waveforms of moderate magnitude $\left(M_{s} \geq \sim 5\right)$ regional earthquakes located around the periphery of the North America continent, the reported $V_{s}$ values presumably represent the isotropic $V_{s}$, which is approximately the mean of $V_{\mathrm{SH}}$ and $V_{\mathrm{SV}}$. In contrast, the $V_{s}$ values determined in our study are in fact $V_{\mathrm{SV}}$ because our data set contains only Rayleigh waves. Therefore, a $2-6 \%$ radial anisotropy at the uppermost mantle would yield a velocity reduction of $0.05-0.14 \mathrm{~km} / \mathrm{s}$ between our results and the two previous models. This estimate is somewhat smaller than that shown in Figure 16. Further studies to characterize the amount and distribution of both azimuthal and radial anisotropy beneath Canada are needed.

\subsection{Future Efforts}

[77] Although the data set used in constructing NA07 contains considerably more raypaths than earlier versions due to incorporation of additional earthquake sources and the deployment of the temporary U.S. Transportable Array, the data coverage for Canada is still not ideal. Nonetheless, a big advantage of earthquake data is that the seismic energy can penetrate to great depths, and thus, earthquake tomography is often capable of resolving deep structures. In contrast, ambient seismic noise tomography does not require welldistributed earthquake sources but the data generally do not have sufficient low-frequency energy to resolve velocity anomalies at depth.

[78] One possible effort is to take a hybrid approach to integrate the data constraints from both earthquake and ambient noise sources. We have experimented with this approach by incorporating a small set of earthquake dispersion curves [Darbyshire, 2005; Darbyshire et al., 2007] into our analysis, but so far with limited success. Taking the phase velocity measurements for the station pair ATGO-ATKO as an example, the dispersion curve derived from ambient seismic noise has good $\mathrm{S} / \mathrm{N}$ in the $3-23 \mathrm{~s}$ period range, whereas the dispersion curve from earthquake data spans 24-186 s. However, there is a sudden $0.1 \mathrm{~km} / \mathrm{s}$ jump between the upper end of the ambient noise dispersion curve and the lower end of the earthquake one. Similar discrepancy was described previously and thought to be the result of differences in the sensitivity kernels for surface waves from earthquakes and those contained in the ambient seismic noise [e.g., Yao et al., 2006].

[79] We suspect the jump to be an artifact arising from the different processing procedures and controlling parameters employed in different studies (e.g., the assumed number of cycles between station pairs). Several other recent efforts of joint interpretation of ambient seismic noise and earthquake dispersion data also observed a discrepancy between earthquake and ambient noise dispersion curves, although the disagreement was smaller and diminished as more earthquake measurements are added to the data set [e.g., Moschetti et al., 2010a; Shen et al., 2013; Zhou et al., 2012]. In other words, it may not be appropriate to simply combine dispersion measurements found in the literature with the seismic ambient noise dispersion curves to form a hybrid data set. A systematic and uniform reprocessing of an expanded data set is probably necessary to ensure internal consistency.

[80] A logical next step to better resolve the crustal thickness and velocity structures of our model is to combine constraints from dispersion data and other types of measurements that are more sensitive to velocity contrast at depths. This can be achieved, for example, by jointly inverting receiver functions with dispersion curves, as demonstrated by the recent study of Shen et al. [2013] for the central and western U.S. A similar effort for Canada is planned in the near future.

[81] Finally, our results can provide important constraints on the density distribution within the crust. Given the relatively flat surface topography throughout most of the cratonic region, the observed relief of the crust-mantle transition cannot be interpreted as an Airy isostatic effect (i.e., lateral density contrasts must exist). Furthermore, an overall correlation between a relatively thick crust $(>40 \mathrm{~km})$ and a relatively high Moho $V_{s}(\geq 4.25 \mathrm{~km} / \mathrm{s})$ can be established for the cratonic region (Figure 13). Such correlation could be qualitatively explained in terms of local density variations according to the linear velocity-density relationship determined from laboratory data for continental crustal materials [Christensen and Mooney, 1995]. However, a quantitative approach to determine the density and temperature distributions from our tomography model is not straightforward: that analysis is the focus of a forthcoming paper (Currie et al., manuscript in preparation, 2013).

\section{Conclusions}

[82] The long geological evolution of Canada has involved many tectonic processes operating over an area of 10 million $\mathrm{km}^{2}$ and a time span of 4 Gyr. This paper presents the first continental-scale study of the shear velocity structure of Canada and the adjacent region using ambient noise tomography, providing better resolution and more homogeneous coverage than previous tomographic studies based on earthquake waveforms.

[83] The vertical component of continuous waveform data between 2003 and 2009 from 788 broadband seismograph stations in Canada and adjacent regions are collected and processed following the procedures described in Bensen et al. [2007]. Stacked cross-correlation functions of all station pairs are analyzed with a phase-matching filter to obtain both the group and phase velocity dispersion curves of the Rayleigh wave. The dispersion measurements for regions overlapping with previous studies are consistent with published results and our results indicate that improvement in the signal-to-noise ratio of the stacked waveforms becomes marginal once the amount of data exceeds 3 years.

[84] Surface wave tomography inversion is carried out from the dispersion data to estimate the phase and group velocity distribution at $1^{\circ}$ interval for periods between 5 and $100 \mathrm{~s}$. In general, the patterns of group and phase velocity distributions are similar to each other at all periods. At shorter periods (e.g., $10 \mathrm{~s}$ ), prominent low velocity anomalies are observed in the Gulf of St. Lawrence in the east, the sedimentary basins of west Canada, and the Cordillera. In contrast, the Canadian Shield exhibits high velocities. The velocity contrast between high and low anomalies becomes smaller at longer periods (e.g., $\geq 35 \mathrm{~s}$ ), and the high velocities associated with the craton appear to expand slightly toward the west under the western Canadian sedimentary basin.

[85] For each grid point, a 1-D shear velocity $\left(V_{s}\right)$ profile is inverted from the dispersion data using the neighborhood algorithm [Sambridge, 1999a, 1999b]. The resulted $4949 V_{s}$ 
profiles are then combined into a pseudo 3-D $V_{s}$ model that extends down to $\sim 100 \mathrm{~km}$ depth. Overall, the inner part of the Canadian Shield has $V_{s}$ consistently lower than that of the outer rim throughout the mantle depths resolvable by our data.

[86] To better characterize the nature of crust-mantle transition, we propose that both the thickness and the amount of velocity increase should be included in addition to the depth and velocity of the Moho discontinuity. In this study, the ambient noise Moho is defined as the depth where the $V_{s}$ increase is $85 \%$ from the typical value in the lower crust to uppermost mantle (Figure $13, Z_{85 \%}$ and $V_{85 \%}$ ). Such defined Moho is slightly different from other types (e. g., reflection Moho, refraction Moho, or electric Moho), but the difference is generally less than $5 \mathrm{~km}$. The thickness of crust-mantle transition is defined as the depth difference between places where the crust-mantle $V_{s}$ increase is $50 \%$ and $85 \%$ (Figure 13 , the $\mathrm{dZ}_{50 \%-85 \%}$ ). We have observed considerable variations in the depth, $V_{s}$, and sharpness of the crust-mantle transition across Canada. For the cratonic region, an overall correlation among the crustal thickness, Moho $V_{s}$, and the thickness of the transition can be recognized except in the Hudson Bay area where the Moho $V_{s}$ is relatively low. Such correlation does not seem to hold for the Canadian Cordillera, either, where a modestly sharp transition is associated with thin crust and low Moho $V_{s}$.

[87] Prominent midcrust $V_{s}$ gradient is observed beneath the Cordillera and in the craton beneath part of the Canadian Shield. While the midcrust velocity contrast beneath the Cordillera may be related to a detachment zone due to the consistently high temperature beneath, the large midcrust velocity gradient beneath the Canadian Shield could be interpreted as an ancient rheological boundary between the upper and lower crust with an average mix of $45 \%$ granitic gneiss and $5 \%$ amphibolite in the upper crust and $15 \%$ granitic gneiss and $35 \%$ amphibolite in the lower crust.

[88] Quantitative comparison of our tomography results with previous earthquake-based tomography models reveals that the $V_{s}$ derived from ambient seismic noise is slightly lower (by $\sim 0.2 \mathrm{~km} / \mathrm{s}$ at 70 and $90 \mathrm{~km}$ depths). This is likely caused by the effect of radial anisotropy in the uppermost mantle. An initial attempt to build a hybrid data set containing dispersion measurements from both ambient noise and earthquakes was not successful because the measurements are internally inconsistent. A systematic and uniform reprocessing of an expanded data set is probably necessary for this approach to work. Other research efforts in our plan include extending the current study to Love waves, characterizing the amount and distribution of both azimuthal and radial anisotropy beneath Canada, and estimating the density and temperature distributions from our tomography model.

[89] Acknowledgments. We are grateful to an anonymous Associate Editor, an anonymous reviewer, and Lapo Boschi for their constructive comments. Fiona Darbyshire kindly provided the dispersion measurements of earthquake surface waves. Digital waveform data were obtained from the data centers of the Canadian Hazard Information Service and Incorporated Research Institutions for Seismology. We benefited from discussion with David Schneider, Sonya Dehler, and Yu-Lien Yeh. YB and JT acknowledge the support of the Marsden Fund of the Royal Society of New Zealand. MHR acknowledges support from US NSF grant EAR-1252085. This research was partially supported by a NSERC grants to HK (RGPIN 418268-2013) and to Currie and Hyndman. ESS contribution number 20130238.

\section{References}

Adams, L. H., and E. D. Williamson (1923), Density distribution of the Earth, J. Wash. Acad. Sci., 13, 413-428.

Audet, P., and J. C. Mareschal (2004), Variations in elastic thickness in the Canadian Shield, Earth Planet. Sci. Lett., 226, 17-31, doi:10.1016/j. epsl.2004.1007.1035.

Bank, C.-G., M. G. Bostock, R. M. Ellis, and J. F. Cassidy (2000), A reconnaissance teleseismic study of the upper mantle and transition zone beneath the Archean Slave craton in NW Canada, Tectonophysics, 319(3), 151-166, doi:10.1016/S0040-1951(1000)00034-00032.

Barmin, M. P., M. H. Ritzwoller, and A. L. Levshin (2001), A fast and reliable method for surface wave tomography, Pure Appl. Geophys., 158, $1351-1375$.

Barmine, M., and M. Rtizwoller (2012), IRIS DMS product, western U.S. ambient noise cross correlations, Incorporated Research Institutions for Seismology. Last accessed 26 March 2013, http://www.iris.edu/dms/products/ancc-ciei (published electronically June 2012).

Barruol, G., P. G. Silver, and A. Vauchez (1997), Seismic anisotropy in the eastern United States: Deep structure of a complex continental plate, J. Geophys. Res., 102, 8329-8348.

Bassin, C., G. Laske, and G. Masters (2000), The current limits of resolution for surface wave tomography in North America, EOS Trans. AGU, 81, F897.

Bedle, H., and S. van der Lee (2009), S velocity variations beneath North America, J. Geophys. Res., 114, B07308, doi:10.1029/02008JB005949.

Behr, Y., J. Townend, S. Bannister, and M. K. Savage (2010), Shearvelocity structure of the Northland Peninsula, New Zealand, inferred from ambient noise correlations, J. Geophys. Res., 115, B05309, doi:10.1029/ 2009JB006737.

Behr, Y., J. Townend, S. Bannister, and M. K. Savage (2011), Crustal shear wave tomography of the Taupo Volcanic Zone, New Zealand, via ambient noise correlation between multiple three-component networks, Geochem. Geophys., Geosyst., 12, Q03015, doi:10.1029/02010GC003385.

Bensen, G. D., M. H. Ritzwoller, M. P. Barmin, A. L. Levshin, F. Lin, M. P. Moschetti, N. M. Shapiro, and Y. Yang (2007), Processing seismic ambient noise data to obtain reliable broad-band surface wave dispersion measurements, Geophys. J. Int., 169, 1239-1260, doi:10.1111/j.13651246X.2007.03374.X.

Bensen, G. D., M. H. Ritzwoller, and N. M. Shapiro (2008), Broadband ambient noise surface wave tomography across the United States, J. Geophys. Res., 113, B05306, doi:10.1029/02007JB005248.

Bensen, G. D., M. H. Ritzwoller, and Y. Yang (2009), A 3-D shear velocity model of the crust and uppermost mantle beneath the United States from ambient seismic noise, Geophys. J. Int., 177(3), 1177-1196.

Brown, D., S. Llana-Funez, R. Carbonell, J. Alvarez-Marron, D. Marti, and M. Salisbury (2009), Laboratory measurements of P-wave and S-wave velocities across a surface analog of the continental crust-mantle boundary: Cabo Ortegal, Spain, Earth Planet. Sci. Lett., 285(1-2), 27-38.

Burov, E., C. Jaupart, and J. C. Mareschal (1998), Large-scale crustal heterogeneities and lithospheric strength in cratons, Earth Planet. Sci. Lett., 164(1-2), 205-219.

Cannon, W. F., et al. (1989), The North American Midcontinent Rift beneath Lake Superior from GLIMPCE seismic reflection profiling, Tectonics, 8(2), 305-332.

Cassidy, J. F. (1995), Review: Receiver function studies in the southern Canadian Cordillera, Can. J. Earth Sci., 32, 1514-1519.

Catchings, R. D., and W. D. Mooney (1991), Basin and Range crustal and upper mantle structure, northwest to central Nevada, J. Geophys. Res., 96(B4), 6247-6267.

Cheng, L. Z., J. C. Mareschal, C. Jaupart, F. Rolandone, C. Gariépya, and M. Radigon (2002), Simultaneous inversion of gravity and heat flow data: Constraints on thermal regime, rheology and evolution of the Canadian Shield crust, J. Geodyn., 34, 11-30, doi:10.1016/S02643707(1001)00082-00085.

Christensen, N. I. (1996), Poisson's ratio and crustal seismology, J. Geophys. Res., 101, 3139-3156.

Christensen, N. I., and W. D. Mooney (1995), Seismic velocity structure and composition of the continental crust: A global view, J. Geophys. Res., 100, 9761-9788.

Clowes, R. M., A. G. Green, C. J. Yorath, E. R. Kanasewich, G. F. West, and G. D. Garland (1984), LITHOPROBE-A national program for studying the third dimension of geology, J. Can. Soc. Exp. Geophys., 20, 23-39.

Clowes, R. M., P. T. C. Hammer, G. Fernandez-Viejo, and J. K. Welford (2005), Lithospheric structure in northwestern Canada from Lithoprobe seismic refraction and related studies: A synthesis, Can. J. Earth Sci., 42(6), 1277-1293.

Cook, F. (2002), Fine structure of the continental reflection Moho, Geol. Soc. Am. Bull., 114(1), 64-79. 
Cook, F. A., D. J. White, A. G. Jones, D. W. S. Eaton, J. Hall, and R. M. Clowes (2010), How the crust meets the mantle: Lithoprobe perspectives on the Mohorovicic discontinuity and crust-mantle transition, Can. J. Earth Sci., 47(4), 315-351, doi:10.1139/E1109-1076.

Currie, C. A., and R. D. Hyndman (2006), The thermal structure of subduction zone back arcs, J. Geophys. Res., 111, B08404, doi:10.1029/ 02005 JB004024.

Currie, C. A., J. F. Cassidy, R. D. Hyndman, and M. G. Bostock (2004), Shear wave anisotropy beneath the Cascadia subduction zone and western North American craton, Geophys. J. Int., 157, 341-353, doi:10.1111/ j.1365-1246X.2004.02175.x.

Dalton, C. A., G. Ekström, and A. M. Dziewonski (2009), Global seismological shear velocity and attenuation: A comparison with experimental observations, Earth Planet. Sci. Lett., 284, 65-75, doi:10.1016/j. eps1.2009.1004.1009

Darbyshire, F. A. (2005), Upper mantle structure of Arctic Canada from Rayleigh wave dispersion, Tectonophysics, 405, 1-23.

Darbyshire, F. A., D. W. Eaton, A. W. Frederiksen, and L. Ertolahti (2007), New insights into the lithosphere beneath the Superior Province from Rayleigh wave dispersion and receiver function analysis, Geophys. J. Int., 169, 1043-1068, doi:10.1111/j.1365-1246X.2006.03259.x.

Dunkin, J. W. (1965), Computation of modal solutions in layered, elastic media at high frequencies, Bull. Seismol. Soc. Am., 55, 335-358.

Dziewonski, A. M., and D. L. Anderson (1981), Preliminary reference Earth model, Phys. Earth Planet. Inter., 25, 297-356.

Eakin, C. M., M. Obrebski, R. M. Allen, D. C. Boyarko, M. R. Brudzinski, and R. Porritt (2010), Seismic anisotropy beneath Cascadia and the Mendocino triple junction: Interaction of the subducting slab with mantle flow, Earth Planet. Sci. Lett., 297(3-4), 627-632.

Flück, P., R. D. Hyndman, and C. Lowe (2003), Effective elastic thickness Te of the lithosphere in western Canada, J. Geophys. Res., 108(B9), 2430, doi:10.1029/2002JB002201.

Fountain, D. M., and N. Christensen (1989), Composition of the continental crust and upper mantle: A review, in Geophysical Framework of the Continental United States, Geol. Soc. Am. Memoir 172, edited by L. C. Pakiser and W. D. Mooney, pp. 711-742, Geological Society of America, Boulder, Colo.

Frederiksen, A. W., M. G. Bostock, J. C. VanDecar, and J. F. Cassidy (1998), Seismic structure of the upper mantle beneath the northern Canadian Cordillera from teleseismic travel-time inversion, Tectonophysics, 294, 43-55.

Frederiksen, A. W., S.-K. Miong, F. A. Darbyshire, D. W. Eaton, S. Rondenay, and S. Sol (2007), Lithospheric variations across the Superior Province, Ontario, Canada: Evidence from tomography and shear wave splitting, J. Geophys. Res., 112, B07318, doi:10.1029/02006JB004861.

Fulton, R. J. (1989), Quaternary Geology of Canada and Greenland, Geology of Canada 1, Can. Gov. Pub. Centre, Ottawa, Toronto, Canada, ISBN:0660131145.

Green, D. H., and A. E. Ringwood (1972), A comparison of recent experimental data on the gabbro-garnet granulite-eclogite phase transition, J. Geology, 80(3), 277-288, doi:10.1086/627731.

Guillou-Frottier, L., C. Jaupart, J. C. Mareschal, C. Gariépy, G. Bienfait L. Z. Cheng, and R. Lapointe (1996), High heat flow in the trans-Hudson Orogen, central Canadian Shield, Geophys. Res. Lett., 23(21), 3027-3030, doi:10.1029/3096GL02895.

Hyndman, R. D., and C. A. Currie (2011), Why is the North America Cordillera high? Hot backarcs, thermal isostasy, and mountain belts, Geology, 39(8), 783-786, doi:10.1130/G31998.31991.

Hyndman, R. D., and T. S. Lewis (1999), Geophysical consequences of the Cordillera - Craton thermal transition in southwestern Canada, Tectonophysics, 306, 397-422, doi:10.1016/S0040-1951(1099)00068-00062.

Hyndman, R. D., P. Flück, S. Mazzotti, T. J. Lewis, J. Ristau, and L. Leonard (2005), Current tectonics of the northern Canadian Cordillera, Can. J. Earth Sci., 42, 1117-1136, doi:10.1139/E1105-1023.

Hyndman, R. D., C. A. Currie, S. Mazzotti, and A. Frederiksen (2009), Temperature control of continental lithosphere elastic thickness, Te vs Vs, Earth Planet. Sci. Lett., 277, 539-548.

Ito, K., and G. C. Kennedy (1971), An experimental study of the basaltgarnet granulite-eclogite transition, in The Earth Beneath the Continents, edited by J. G. Heacock, pp. 303-314, AGU Geophysical Monograph 14 Washington, D. C.

Jones, A. G., and I. J. Ferguson (2001), The electric Moho, Nature, 409(6818), 331-333.

Klemperer, S. L., T. A. Hauge, E. C. Hauser, J. E. Oliver, and C. J. Potter (1986), The Moho in the northern Basin and Range province, Nevada, along the COCORP 400N seismic reflection transect, Geol. Soc. Am. Bull., 97(5), 603-618.

Lebedev, S., and R. D. van der Hilst (2008), Global upper-mantle tomography with the automated multimode inversion of surface and S-wave forms, Geophys. J. Int., 173, 505-518, doi:10.1111/j.13651246X.2008.03721.x.
Lebedev, S., J. M. C. Adam, and T. Meier (2013), Mapping the Moho with seis mic surface waves: A review, resolution analysis, and recommended inversion strategies, Tectonophysics, doi:10.1016/j.tecto.2012.1012.1030, in press. Lekic, V., and B. Romanowicz (2011), Tectonic regionalization without a priori information: A cluster analysis of upper mantle tomography, Earth Planet. Sci. Lett., 308(1-2), 151-160.

Leveque, J.-J., L. Rivera, and G. Wittlinger (1993), On the use of the checkerboard test to assess the resolution of tomographic inversion, Geophys. J. Int. $115,313-318$

Levin, V., W. Menke, and J. Park (1999), Shear wave splitting in the Appalachians and the Urals: A case for multilayered anisotropy, J. Geophys. Res., 104, 17,975-17,993.

Levshin, A. L., and M. H. Ritzwoller (2001), Automated detection, extraction, and measurement of regional surface waves, Pure Appl. Geophys. 158(8), 1531-1545

Lin, F.-C., M. H. Ritzwoller, J. Townend, S. Bannister, and M. Savage (2007), Ambient noise Rayleigh wave tomography of New Zealand, Geophys. J. Int., doi:10.1111/j.1365-1246X.2007.03414x.

Lin, F.-C., M. P. Moschetti, and M. H. Ritzwoller (2008), Surface wave tomography of the western United States from ambient seismic noise: Rayleigh and Love wave phase velocity maps, Geophys. J. Int., 173(1), 281-298, doi:10.1111/j.1365-1246X.2008.03720.x.

Ma, K.-F., Y.-Y. Lin, S.-J. Lee, J. Mori, and E. E. Brodsky (2012), Isotropic events observed with a borehole array in the Chelungpu fault zone, Taiwan, Science, 337(459), 459-463, doi:10.1126/science.1222119.

Mareschal, J. C., C. Jaupart, F. Rolandone, C. Gariépy, C. M. R. Fowler, G. Bienfait, C. Carbonne, and R. Lapointe (2005), Heat flow, therma regime, and elastic thickness of the lithosphere in the Trans-Hudson Orogen, Can. J. Earth Sci., 42(4), 517-532, doi:10.1139/e1104-1088.

Mazzotti, S., and R. D. Hyndman (2002), Yakutat collision and strain transfer across the northern Canadian Cordillera, Geology, 30, 495-498.

Mercier, J.-P., M. G. Bostock, J. F. Cassidy, K. Dueker, J. B. Gaherty, E. J. Garnero, J. Revenaugh, and G. Zandt (2009), Body-wave tomography of western Canada, Tectonophysics, 475, 480-492, doi:10.1016/ j.tecto.2009.1005.1030.

Mohorovicic, A. (1910), Das Beben Vom 8. x. 1909, in Jahrbuch Meterologie Observatorie Zagrab, vol. 9, pp. 1-63, Zagreb University, Zagreb, Yugoslavia.

Mooney, W. D. (1987), Seismology of the continental crust and upper mantle, Rev. Geophys., 25, 1168-1176.

Mooney, W. D., and T. M. Brocher (1987), Coincident seismic reflection/ refraction studies of the continental lithosphere: A global review, Rev. Geophys., 25, 723-742

Mooney, W. D., G. Laske, and T. G. Masters (1998), CRUST 5.1: A global crustal model at $5^{\circ} \times 5^{\circ}, J$. Geophys. Res., 103, 727-747.

Moores, E. M. (1982), Origin and emplacement of ophiolites, Rev. Geophys. Space Phys., 20(4), 735-760.

Moschetti, M. P., M. H. Ritzwoller, F. C. Lin, and Y. Yang (2010a), Crustal shear wave velocity structure of the western United States inferred from ambient seismic noise and earthquake data, J. Geophys. Res., 115, B10306, doi:10.1029/12010JB007448.

Moschetti, M. P., M. H. Ritzwoller, F. Lin, and Y. Yang (2010b), Seismic evidence for widespread western-US deep-crustal deformation caused by extension, Nature, 464(7290), 885-889, doi:10.1038/nature08951.

Nettles, M., and A. M. Dziewonski (2008), Radially anisotropic shear velocity structure of the upper mantle globally and beneath North America J. Geophys. Res., 113, B02303, doi:10.1029/02006JB004819.

Okulitch, A. V., and H. Trettin (1991), Late Cretaceous to Early Tertiary deformation, Arctic Islands, in Geology of the Innuitian Orogen and Arctic Platform of Canada and Greenland, edited by H. P. Trettin, pp. 469-489, Geol. Surv., Canada, Ottawa.

Pawlak, A., D. W. Eaton, I. D. Bastow, J.-M. Kendall, G. Helffrich, J. Wookey, and D. Snyder (2010), Crustal structure beneath Hudson Bay from ambientnoise tomography: Implications for basin formation, Geophys. J. Int., 181 65-82, doi:10.1111/j.1365-1246X.2010.04828.x.

Perry, H. K. C., D. W. S. Eaton, and A. M. Forte (2002), LITH5.0: A revised crustal model for Canada based on Lithoprobe results, Geophys. J. Int., $150,285-294$

Perry, H. K. C., C. Jaupart, J.-C. Mareschal, and G. Bienfait (2006), Crustal heat production in the Superior Province, Canadian Shield, and in North America inferred from heat flow data, J. Geophys. Res., 111, B04401, doi:10.1029/02005JB003893.

Richter, C. F. (1958), Elementary Seismology, 712 pp., W. H. Freeman and Company, San Francisco, Library of Congress Catalogue Card Number $58-5970$

Rieger, D. M., and J. Park (2010), USArray observations of quasi-Love surface wave scattering: Orienting anisotropy in the Cascadia plate boundary, J. Geophys. Res., 115, B05306, doi:10.1029/02009JB006754.

Ritzwoller, M. H., F.-C. Lin, and W. Shen (2011), Ambient noise tomography with a large seismic array, C. R. Geosci., 343, 558-570, doi:10.1016/j. crte.2011.1003.1007. 


\section{KAO ET AL.: AMBIENT NOISE TOMOGRAPHY OF CANADA}

Sabra, K. G., P. Gerstoft, P. Roux, W. A. Kuperman, and M. C. Fehler (2005), Surface wave tomography from microseisms in Southern California, Geophys. Res. Lett., 32, L14311, doi:10.1029/12005GL023155.

Sambridge, M. (1999a), Geophysical inversion with a neighbourhood algorithm-II. Appraising the ensemble, Geophys. J. Int., 138, 727-746.

Sambridge, M. (1999b), Geophysical inversion with a neighbourhood algorithm-I. Searching a parameter space, Geophys. J. Int., 138, 479-494.

Shapiro, N. M., M. H. Ritzwoller, P. Molnar, and V. Levin (2004a), Thinning and flow of Tibetan crust constrained by seismic anisotropy, Science, 305, 233-236, doi:10.1126/science.1098276.

Shapiro, N. M., M. H. Ritzwoller, J. C. Mareschal, and C. Jaupart (2004b), Lithospheric structure of the Canadian Shield inferred from inversion of surface-wave dispersion with thermodynamic a priori constraints, Geol. Soc. London Special Pub., 239, 175-194, doi:10.1144/ GSL.SP.2004.1239.1101.1112.

Shapiro, N. M., M. Campillo, L. Stehly, and M. H. Ritzwoller (2005), Highresolution surface-wave tomography from ambient seismic noise, Science, 307(5715), 1615-1618.

Shen, W., M. H. Ritzwoller, and V. Schulte-Pelkum (2013), A 3-D mode of the crust and uppermost mantle beneath the central and western US by joint inversion of receiver functions and surface wave dispersion, J. Geophys. Res. Solid Earth, 118, 1-15, doi:10.1029/2012JB009602.

Simmons, N. A., A. M. Forte, L. Boschi, and S. P. Grand (2010), GyPSuM: A joint tomographic model of mantle density and seismic wave speeds, J. Geophys. Res., 115, B12310, doi:10.1029/12010JB007631.

Simons, F., R. D. van der Hilst, J.-P. Montagner, and A. Zielhuis (2002), Multimode Rayleigh wave inversion for heterogeneity and azimuthal anisotropy of the Australian upper mantle, Geophys. J. Int., 151, 738-754

Stehly, L., M. Campillo, and N. M. Shapiro (2006), A study of the seismic noise from its long-range correlation properties, J. Geophys. Res., 111, B10306, doi:10.1029/12005JB004237.

Steinhart, J. S. (1967), Mohorovicic discontinuity, in International Dictionary of Geophysics, edited by S. K. Runcorn, pp. 991-994, Pergamon Press, Oxford, U. K.

Tibuleac, I. M., D. H. von Seggern, J. G. Anderson, and J. N. Louie (2011), Computing Green's functions from ambient noise recorded by accelerometers and analog, broadband, and narrow-band seismometers, Seismol. Res. Lett., 82(5), 661-675, doi:10.1785/gssrl.1782.1785.1661.

van der Lee, S., and A. Frederiksen (2005), Surface wave tomography applied to the North American upper mantle, in Seismic Earth: Array Analysis of Broadband Seismograms, edited by G. Nolet, pp. 67-80, AGU Geophysical Monograph 157, Washington, D. C.

Vincent, J. (1989), Quaternary geology of the southeastern Canadian Shield, Ouat. Geol. Canada and Greenland, 1, 249-275.

Wang, Y., and J. Mareschal (1999), Elastic thickness of the lithosphere in the Central Canadian Shield, Geophys. Res. Lett., 26(19), 3033-3036, doi:10.1029/1999GL010806.

Wapenaar, K., D. Draganov, and J. O. A. Robertsson (2008), Seismic Interferometry: History and Present Status, pp. 628, Soc. of Explor. Geophys., Tulsa, OK.

Wathelet, M. (2005), Array recordings of ambient vibrations: Surface wave inversion, $\mathrm{PhD}$ thesis, Faculté des Sciences Appliquées.

Wathelet, M. (2008), An improved neighborhood algorithm: Parameter conditions and dynamic scaling, Geophys. Res. Lett., 35, L09301, doi:10.1029/2008GL033256.

Wheeler, J. O., P. F. Hoffman, K. D. Card, A. Davidson, B. V. Sanford, A. V. Okulitch, and W. R. Roest (1997), Geological Map of Canada, Map D1860A, Geological Survey of Canada, Ottawa.

Williams, H. (1979), Appalachian Orogen in Canada, Can. J. Earth Sci., 16(3), 792-807.

Wu, P. (1991), Flexure of lithosphere beneath the Alberta foreland basin: Evidence of an eastward stiffening continental lithosphere, Geophys. Res. Lett., 18(3), 451-454.

Yao, H., R. D. Van Der Hilst, and M. V. de Hoop (2006), Surface-wave array tomography in SE Tibet from ambient seismic noise and two-station analysis-I. Phase velocity maps, Geophys. J. Int., 166, 732-744, doi:10.1111/j.1365-246X.2006.03028.x.

Yuan, H., and B. Romanowicz (2010), Lithospheric layering in the North American Craton, Nature, 466(7310), 1063-1068, doi:10.1038/nature09332.

Zhou, L., J. Xie, W. Shen, Y. Zheng, Y. Yang, H. Shi, and M. H. Ritzwoller (2012), The structure of the crust and uppermost mantle beneath south China from ambient noise and earthquake tomography, Geophys. J. Int. 189(3), 1565-1583, doi:10.1111/j.1365-1246X.2012.05423.x. 